\title{
Plasma deposition-Impact of ions in plasma enhanced chemical vapor deposition, plasma enhanced atomic layer deposition, and applications to area selective deposition
}

\author{
C. Vallée ${ }^{1,2^{*}}$, M. Bonvalot ${ }^{1 *}$, S. Belahcen ${ }^{1}$, T. Yeghoyan $^{1}$, M. Jaffal ${ }^{1}$, R. Vallat $^{1}$, A. Chaker ${ }^{1,3}$,

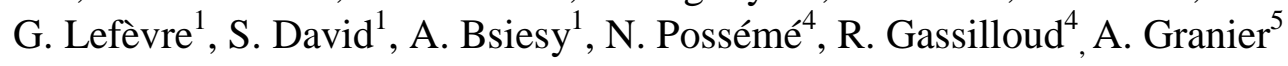 \\ ${ }^{1}$ Univ. Grenoble Alpes, LTM, F-38000 Grenoble, France.
}

${ }^{2}$ University of Tsukuba, Tsukuba 305-8573, Japan

${ }^{3}$ School of Chemistry and Photon Science Institute, the University of Manchester, Oxford Road, Manchester M13 9PL, United Kingdom

${ }^{4}$ CEA, LETI, Minatec Campus, F-38054 Grenoble, France.

${ }^{5}$ Institut des Matériaux Jean Rouxel (IMN), UMR CNRS 6502, Nantes, France

*corresponding authors: christophe.vallee@cea.fr and marceline.bonvalot@cea.fr

\begin{abstract}
In this paper, the emerging role of ionic species in plasma assisted chemical deposition processes is discussed in details for commemorating the Career of John Coburn who studied the role of ionic species in plasma etching processes forty years ago. It is shown that in both Plasma Enhanced Chemical Vapor Deposition (PECVD) and Plasma Enhanced Atomic Layer Deposition (PEALD) processes, plasma ions can play a major role in tuning a wide range of physical properties of thin films. In both processes, the possibility of extracting plasma ions with a tunable incident kinetic energy driven on the substrate surface is shown to provide a valuable additional degree of freedom in plasma processing. While a too large incident kinetic energy of plasma ions may have damaging effects linked to surface sputtering and atomic peening, a relatively low energy ion bombardment ensures a substantial improvement of thin film purity and the effective tuning of its microstructural properties. This phenomenon is attributed to the synergetic effect boosting momentum transfer and chemical reactivity among radicals and ionic plasma species which in turn modulates plasma-surface interactions. Taking advantage of these tunable physical properties opens up the way to a large array of pathways for selective deposition processes in both $2 \mathrm{D}$ and $3 \mathrm{D}$ nanoscale microstructures.
\end{abstract}




\section{INTRODUCTION}

Forty years ago, a paper entitled «Plasma etching - A discussion of mechanisms » was published in the Journal of Vacuum and Science and Technology by J.W. Coburn and H.F Winters ${ }^{1}$. In this paper, the authors reported on plasma etching mechanisms based on a simple set of experiments emphasizing on the role of both ions and radicals in a Reactive Ion Etching process. Today, no plasma etching lecture can be given without a citation of the Coburn and Winters paper accounting for the ion/radical synergetic effect in a plasma etching process ${ }^{1-2}$. This synergetic effect between both chemical and physical plasma components not only leads to significantly enhanced plasma etching rates, but also enables anisotropic etching, which has proven to be crucial for device downscaling in the microelectronics industry.

Plasmas have also been extensively used in thin film deposition processes. However, in contrast to etching processes, it is most common to take advantage of ions and radicals within the plasma in a separate manner. For instance, in Physical Vapor Deposition (PVD) sputtering processes, the deposition rate essentially relies on the kinetic energy of plasma ions whereas in

Plasma Enhanced Chemical Vapor Deposition (PECVD), plasma reactors using capacitive discharges are operated under high pressure regimes in order to limit ion bombardment. A turning point came in the 90's with the emergence of inductively coupled plasma sources, where plasmas operate in a remote way that limit ion-induced plasma damage on layers under growth. At the beginning of this new century, a new CVD-derived technique, namely Atomic Layer Deposition (ALD) penetrated the semiconductor industry thanks to its unequalled benefits of conformality enabling 3D deposition, thickness control at atomic scale, etc. Shortly after, and thanks to the experience gained in developing plasma assistance for CVD, Plasma Enhanced ALD (PEALD) emerged and further spread the use of ALD in advanced thin film deposition.

It is interesting to underline here that this plasma assistance in both CVD and ALD processes has been systematically developed with the overall accepted idea that only plasma radicals and neutral species should participate in the deposition process itself, due to detrimental effects induced by ion bombardment. Indeed, several studies have indicated that charged species from the plasma are responsible for plasma-induced damages in the layer under growth, such as roughness, defects, porosity, or unwanted electrical charges implanted in the sub-dielectrics ${ }^{3-7}$. With the development of high-density low-pressure plasma sources in the $90^{\text {th }}$, for which the energy of ions is controlled independently to the plasma production, 
many authors have studied the use of ions in PECVD processes ${ }^{8-22}$. More recently, it has also been suggested that one could also take advantage of ions in PEALD processes to optimize the physical properties of the layer under growth ${ }^{23-29}$.

In this paper dedicated to the memory of J.W. Coburn and H.F Winters, we will discuss the mechanisms of plasma assisted deposition processes with special attention devoted to the role played by ions; three examples will be discussed: PECVD, PEALD, and area selective deposition processes. For each process, we will emphasize the role of ion assistance and its benefits.

\section{PECVD process: ions versus radicals}

Figure 1 summarizes the synergetic effect observed by Coburn and Winters in their original paper when using both ions and radicals for plasma etching ${ }^{1-2}$. The main reason for this strong enhancement is that ions provide energy to the surface to promote or enhance any chemical reaction needed to form the volatile end product. A high etch rate can only be achieved if both chemical and physical components are present. Nevertheless, this synergetic effect can only be observed in reactions when the final product is volatile.

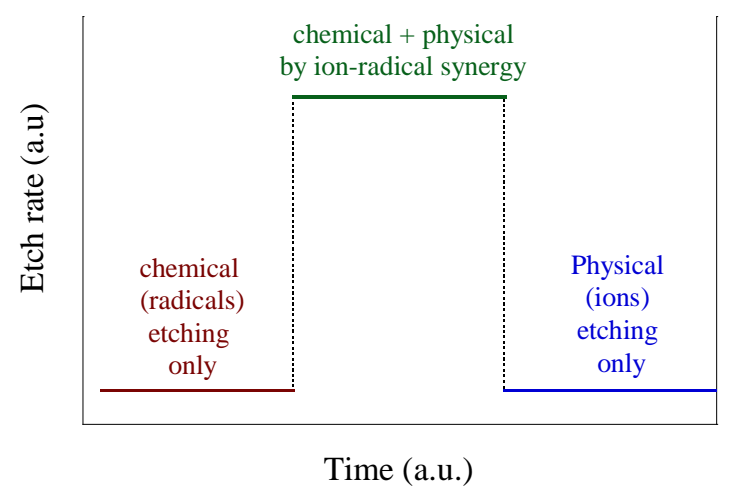

FIG. 1. (Color online) Schematic of the synergetic effect on etching rate when using both ions and radicals. Adapted with permission from J. W. Coburn and Harold F. Winters, J. Appl. Phys. 50, 3189 (1979), Copyright 1979 American Institute of Physics.

In agreement with the paper of Coburn and Winters, the chemical reactions whose kinetics can be enhanced by ions are mainly ${ }^{1}$ : i) non-dissociative adsorption of gas-phase species at the surface, ii) dissociation of these adsorbed gas-phase species, iii) reaction between adsorbed atoms and the solid surface, iv) desorption of the volatile product, v) removal of non-reactive residues. 
Considering a PECVD process, anyone of these but the desorption reaction (iv) can be involved in a deposition process. For this reason, there is no doubt that ion bombardment should somehow be beneficial to a PECVD process as well. However, the main difference is that its energy must be limited during deposition, as opposed to etching. Indeed, a too high incident kinetic energy for impinging ions may lead to heavy surface bombardment inducing sputtering. This in turn will induce an etching process competing with deposition reactions. Table 1 summarizes the expected merit of ions in PECVD processes as a function of their energy $^{8,30-32}$. Examples of ion-film interaction diagrams can be found in the papers from AH.M. Smets et $a l^{8}$ and in the review paper of L. Martinu et $a l^{12}$. Whatever the material deposited, it is observed that low $(10-30 \mathrm{eV})$ or intermediate $(\sim 100 \mathrm{eV})$ ion energies have a positive effect on the material structural properties (density, stress, contamination, etc. $)^{12}$.

\begin{tabular}{|c|c|c|c|}
\hline $\begin{array}{l}\text { Ion energy } \\
\text { range }\end{array}$ & $\begin{array}{c}\text { Consequence of ion } \\
\text { bombardment }\end{array}$ & $\begin{array}{c}\text { Possible impact on film } \\
\text { properties }\end{array}$ & $\begin{array}{l}\text { Impact on } \\
\text { growth rate }\end{array}$ \\
\hline $1-5 \mathrm{eV}$ & $\begin{array}{c}\text { Creation of dangling bonds } \\
\text { Desorption of residues }\end{array}$ & \multirow{2}{*}{$\begin{array}{c}\text { Increase of density } \\
\text { Less contamination } \\
\text { No impact on roughness }\end{array}$} & \multirow[b]{2}{*}{$\begin{array}{l}\text { Increase of } \\
\text { growth rate }\end{array}$} \\
\hline $5-30 \mathrm{eV}$ & $\begin{array}{c}\text { Opening of bonds } \\
\text { Creation of new active sites } \\
\text { Heating of the surface }\end{array}$ & & \\
\hline$>50 \mathrm{eV}$ & Sputtering & \multirow{2}{*}{$\begin{array}{c}\text { Lower density (not always) } \\
\text { Contamination (undesired } \\
\text { doping) } \\
\text { Roughness }\end{array}$} & \multirow[b]{2}{*}{$\begin{array}{l}\text { Decrease of } \\
\text { growth rate }\end{array}$} \\
\hline$>100 \mathrm{eV}$ & Implantation & & \\
\hline
\end{tabular}

Table 1. Effect on ion bombardment as a function of its energy in a PECVD process, data adapted from references ${ }^{8,30-32}$

An example of the impact of ion energy on PECVD process growth rate is given in Figure 2. In their work, R.G. Andosca et al ${ }^{11}$ have modified the ion energy during $\mathrm{SiO}_{2}$ deposition from a $\mathrm{SiH}_{4} / \mathrm{O}_{2}$ microwave plasma discharge. They observed an increase in the growth rate for substrate voltages less than $30 \mathrm{~V}$ (negative value in practice), independent from the substrate temperature. Beyond this value, the sputtering rate component is becoming too large, leading to an overall decrease in the deposition rate. However, a deep understanding of ion bombardment effects during deposition also needs to take into consideration the ion flux as a contributing parameter as well. K.L. Seaward et al ${ }^{20}$ have indeed shown that by 
increasing the ion flux to the surface, the density and stress of deposited $\mathrm{SiO}_{2}$ can be modified. Moreover, the improvement in the $\mathrm{SiO}_{2}$ density is strongly correlated to the decrease in the number of hydroxyl groups in the film.

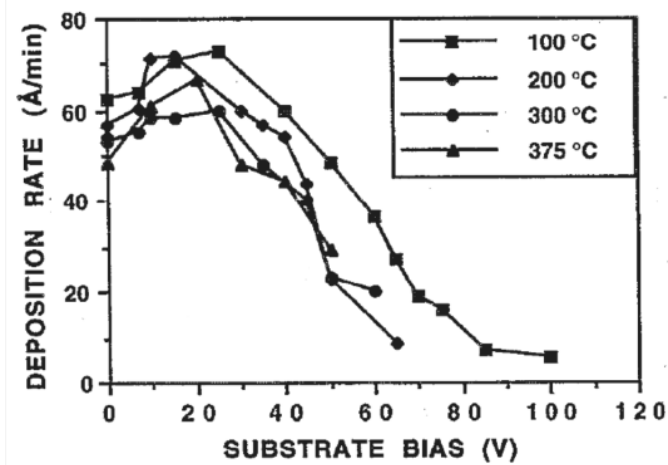

FIG. 2. Impact of temperature and ion energy on the growth rate of $\mathrm{SiO}_{2}$ by $\mathrm{PECVD}$ in a microwave discharge. Reprinted from J. Appl. Phys. 72, 1126 (1992) with the permission of AIP Publishing.

Many studies, essentially dedicated to $\mathrm{SiO}_{2}$ deposition, have been carried out in the 90's in order to understand the exact role of ions in the enhancement of PECVD kinetics. One explanation was given by E.S. Aydil and co-authors ${ }^{21-22}$. They investigated $\mathrm{SiO}_{2}$ deposition by in situ Attenuated Total Reflection Fourier Transform Infrared Spectroscopy to show that when a TEOS based plasma is used, $\mathrm{Si}-\mathrm{O}-\mathrm{Si}$ bonds are formed via reactions between two nearby $\mathrm{Si}-\mathrm{OH}$ species ${ }^{21}$, as illustrated in Figure 3a. Ions such as $\mathrm{O}_{2}{ }^{+}$from the oxygen plasma can indeed assist the reduction of $\mathrm{Si}-\mathrm{OH}$ groups within the deposited film, which in turn increases the growth rate as illustrated in Figure $3 \mathrm{~b}$.

It thus appears that oxygen ions not only participate in the oxidation reactions to form Si-O bonds, but also help remove undesired $\mathrm{H}$ atoms by decreasing the amount of hydroxyl groups in the deposited film. This proves that ions having a specific chemistry and/or energy can also tune the quality/properties of the deposited films by modifying the chemical bonding within the material. However, the untold story in the paper from S.M. Han et $a l^{22}$ is the plasma reactor used for these experiments. For a good control of ion energy, most common plasma reactors are microwave plasma discharge-type or inductively coupled plasma discharge-type, i.e. high density, low pressure, plasma sources (HDP). This is necessary for the independent and precise control of ion energy, which can be achieved thanks to a noncollisional sheath in the vicinity of the substrate. Papers from D. Li and co-authors ${ }^{33-34}$ are a good illustration of this statement. In their work, they studied the impact of ion energy on the chemical composition, optical properties and crystalline structure of $\mathrm{Ti}_{\mathrm{x}} \mathrm{Si}_{1-\mathrm{x}} \mathrm{O}_{2}$ films 
deposited at low temperature and pressure, in an ICP discharge from $\mathrm{O}_{2} / \mathrm{TTIP} / \mathrm{HMDSO}$ plasmas. At $75 \mathrm{eV}$ ion energy (corresponding to a negative voltage of $50 \mathrm{~V}$ applied to the substrate), the Ti/Si ratio in the film is modified, which in turn modified the optical properties of the thin films, as illustrated in table 2. Thanks to an appropriate fraction of $\mathrm{Si}$ atoms injected in the plasma and to ion energy assistance, they were able to obtain a rutile phase at low temperature.
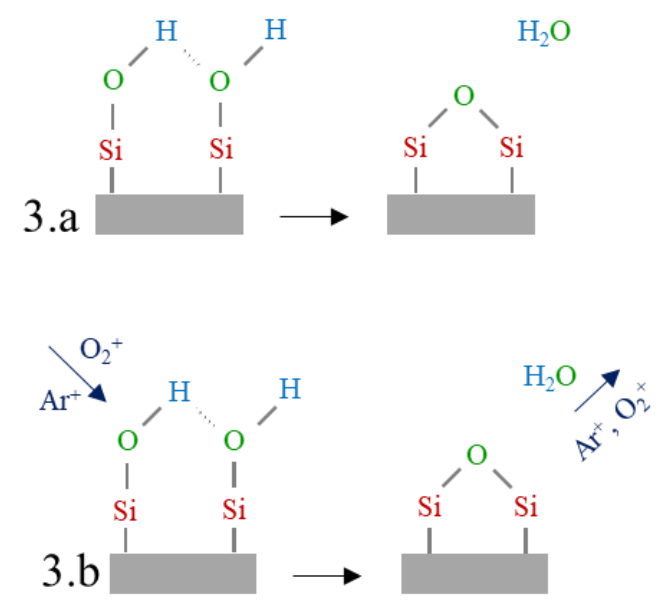

Fig. 3. Schematic illustration of surface reactions in PECVD of $\mathrm{SiO}_{2}$ : (3.a) Formation of Si-OSi bond via reaction between two adjacent hydrogen bonded silanol species; (3.b) Assistance of $\mathrm{O}_{2}{ }^{+}$plasma species for the Si-O-Si bond formation. Adapted with permission from S.M. Han and E.S. Aydil, J. Vac. Sci. Technol. A 14, 2062 (1996), Copyright 1996 by the American Vacuum Society

\begin{tabular}{|c|c|c|c|}
\hline $\begin{array}{c}\text { Fraction of Si atoms } \\
\text { injected in the plasma }\end{array}$ & Ion energy (eV) & Gap Eg (eV) & $\begin{array}{c}\text { Refractive index } \\
\mathrm{n}(\text { at } 632 \mathrm{~nm})\end{array}$ \\
\hline 0.22 & 15 & 3.45 & 1.95 \\
& 75 & 3.25 & 2.24 \\
\hline \multirow{2}{*}{0.41} & 15 & 3.65 & 1.70 \\
& 75 & 3.35 & 2.04 \\
\hline \multirow{2}{*}{0.58} & 15 & 3.79 & 1.65 \\
& 75 & 3.52 & 1.72 \\
\hline \multirow{2}{*}{0.68} & 15 & 3.99 & 1.57 \\
& 75 & 3.68 & 1.50 \\
\hline \multirow{2}{*}{0.74} & 15 & 4.25 & 1.58 \\
\hline
\end{tabular}


Table 2. Bandgap energy (Eg) and refractive index of films deposited from different gas compositions and substrate bias; the ion energy of $15 \mathrm{eV}$ corresponds to the substrate unbiased (at floating voltage) while $75 \mathrm{eV}$ corresponds to $-50 \mathrm{~V}$ applied to the substrate. Adapted with permission from D. Li, S. Dai, A. Goullet, and A. Granier, Plasma Process Polym. 16, 1900034 (2019), Copyright 2019, John Wiley \& Sons, Inc.

Most of the time, a $13.56 \mathrm{MHz}$ RF waveform bias is used to precisely control the ion energy, thanks to the DC self-bias voltage superposed to the RF waveform. But in case of hydrogen-based plasma, due to the low ion mass of ionic species $\left(\mathrm{H}_{\mathrm{x}=1-3}{ }^{+}\right)$the frequency of the generator should be higher. In this case, a pulsed-DC voltage can also be a solution for a good control of the ion energy. In the past, we compared the $\mathrm{sp}^{3}$ to $\mathrm{sp}^{2}$ fraction in Diamond-Like Carbon (DLC) films deposited in a microwave plasma with two different biasing system: 13.56 MHz RF and pulsed-DC bias ${ }^{35}$. When DLC films are exposed to hydrogen ions during their growth, an adequate choice of ion energy enables to efficiently tailor the graphite vs diamond-like structure of the film ${ }^{35-39}$. This is illustrated in figure 4 , where it can be seen that $\mathrm{sp}^{3}$ bonds can be converted to $\mathrm{sp}^{2}$ bonds depending on the negative value of the DC voltage (self-bias or pulsed-DC) applied to the substrate in a $\mathrm{C}_{2} \mathrm{H}_{2}$ Distributed Electron Cyclotron Resonance (DECR) plasma (2.45 GHz).

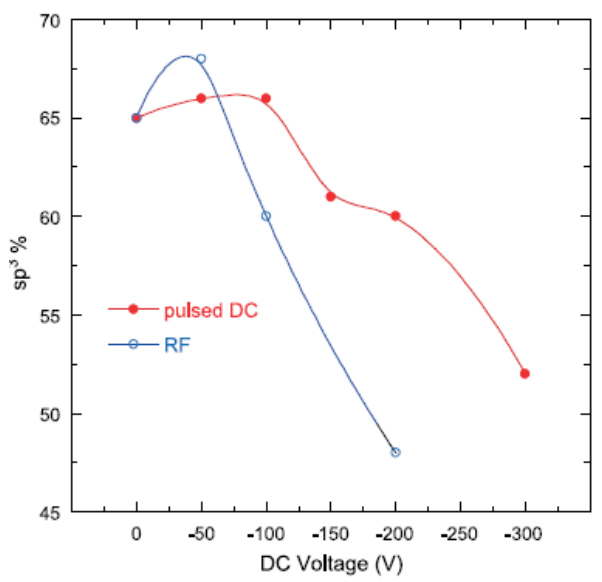

FIG. 4. (Color online) $\mathrm{sp}^{3}$ fraction in a-C:H films deposited in a DECR plasma from $\mathrm{C}_{2} \mathrm{H}_{2}$ as a function of the negative DC voltage developed at the substrate. Reprinted from Surf. Coat. Technol. 186, 146 (2004), F. Thièry et al, PECVD and PIID processing of diamond-like carbon, Copyright (2004), with permission from Elsevier.

Moreover, ions can also help, directly or indirectly, to adjust the quality and growth rate of PECVD films, even in a high pressure capacitive discharge regime, compared to the 
HDP sources and their relatively low pressure. It is also well known that the ion flux influences the compressive to tensile stress transition in dual frequency PECVD deposited $\mathrm{SiN}$ films ${ }^{40}$. In a previous study, we have shown that the growth rate, density and resistivity of a PECVD TiN film deposited in a dual frequency CCP plasma reactor can be tuned by adjusting the low frequency to high frequency power ratio, which modulates the ion energy in the discharge ${ }^{41}$. This regime thus allows gap filling of trenches or vias by PECVD ${ }^{42-44}$. Ions with low energy can also enhance the surface mobility of adsorbed radicals originating from precursor dissociation to facilitate gap filling and 3D feature step coverage. However, as already mentioned, if ion energy is too high, energetic ions can induce undesired dissociation of adsorbed reactive species at the surface, leading to step coverage degradation.

Finally, we must underline the deleterious effect of hot active plasma species in sensitive applications such as for instance transistor gate stack fabrication. Figure 5 shows a gate stack involving a tantalum metal gate within the framework of a gate-last integration scheme, along with a tungsten plug required in advanced middle-end contact technologies. To prevent fluorine diffusion from a $\mathrm{WF}_{6}$ CVD process, a fine $5 \mathrm{~nm}$ thick PECVD TiN barrier is inserted between the Ta gate and the $\mathrm{W}$ plug. I-V and $\mathrm{C}-\mathrm{V}$ measurements of the obtained MOS devices allow the extraction of the silicon flat band voltage $\left(\mathrm{V}_{\mathrm{FB}}\right)$ shift, which depends on the metal work function. This $\mathrm{V}_{\mathrm{FB}}$ is also affected by charged particles trapped at the metal/dielectric interface or within the dielectric itself, whose presence may result from gate stack processing conditions. Tantalum is known to show a n-like work function at 4.1-4.2eV. As evidenced in Figure 5, a $10 \mathrm{~nm}$ thick Ta layer on $\mathrm{SiO}_{2}$ exhibits a large negative $-0.4 \mathrm{~V}$ shift corresponding to the expected metal work function of Ta (mid-gap Si is referenced at $4.6 \mathrm{eV}$ ), which increases exponentially upon Ta thickness reduction due to hot species originating from the PECVD TiN process. Indeed, an $\mathrm{N}_{2} / \mathrm{H}_{2}$ plasma treatment is required in the TiN PECVD process in order to densify TiN and to reduce carbon contaminations from TDMAT precursor decomposition. We have estimated that a minimum Ta thickness of $6 \mathrm{~nm}$ is required to screen these charged particle defects in $\mathrm{SiO}_{2}$. This result again illustrates that plasma ionic species may actually help improve thin film bulk properties but may as well induce side effects in sub-layers. This effect must be evaluated and also taken into account in technological developments, achieved in our case through Ta screening. 


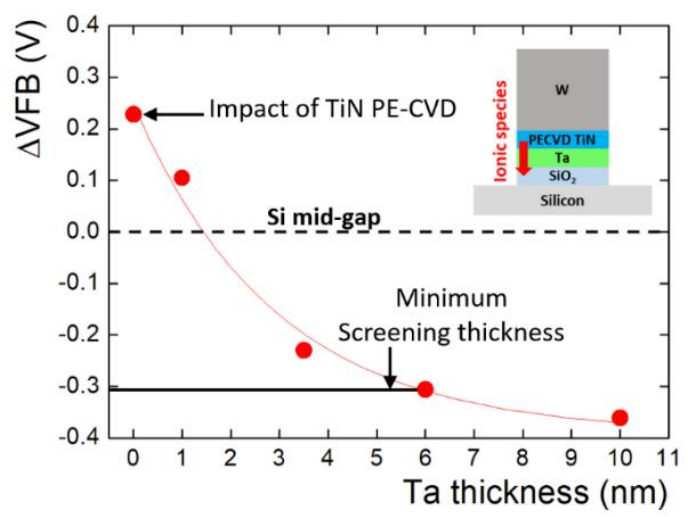

FIG. 5. (Color online) Evolution of the flab band voltage of MOS capacitors with Ta thickness on $2 \mathrm{~nm}-\mathrm{SiO}_{2}$ dielectric using TiN PECVD/W plug technology as gate contact

As a summary, the synergetic effect leading to increased etching rates when adding ions to radicals has never been observed within the same order of magnitude for the counterpart deposition processes, such as PECVD. But low energy ion bombardment during PECVD can nonetheless significantly enhance processes in terms of growth rate and film properties. However, the idea that ions may degrade film properties and induce unwanted plasma damages in PECVD dielectrics films is so deeply rooted that ion bombardment is included only in a few industrial processes in semiconductor device manufacturing.

\section{PEALD process: ions versus radicals}

Nowadays, PEALD processes are used in high volume manufacturing for the conformal deposition of $\mathrm{SiO}_{2}$ or $\mathrm{SiN}$ films needed for spacers or self-aligned double or quadruple patterning fabrication processes ${ }^{45}$. It is most likely that in the near future, the ongoing pace of miniaturization in the microelectronics industry will dictate even more stringent requirements for the development of new PEALD processes. This in turn prompts innovative PEALD developments from academia.

In accordance with the development of plasma assistance in traditional CVD in the late 70's, developing plasma assistance for ALD has been motivated by the possibility of significantly reducing processing temperatures, enabling coating of thermally fragile substrates (textiles, paper, polymers), extending the range of available precursors, and improving the purity and physical properties of the produced thin films ${ }^{46-53}$. To illustrate this, $\mathrm{Al}_{2} \mathrm{O}_{3}$ thin films deposited with TMA have much better insulating and passivation properties when produced by an $\mathrm{O}_{2}$ plasma step, rather than an $\mathrm{H}_{2} \mathrm{O}$ or ozone oxidation step ${ }^{46}$. PEALD deposited materials are most commonly but not limited to metallic or rare earth oxides, 
nitrides or pure metallic elements ( $\mathrm{Ta}, \mathrm{Ti}, \mathrm{Si}, \mathrm{Ge}$, etc). For some specific materials, the use of a highly reactive plasma step cannot be circumvented for the effective reactivation of precursor adsorbates. For example, a $\mathrm{H}_{2}$ or $\mathrm{NH}_{3}$ plasma step is required for AlN deposition with Tri-Methyl Aluminum (TMA) precursor, because a simple exposure to these reducing gases $\left(\mathrm{NH}_{3}\right.$ or $\left.\mathrm{N}_{2} / \mathrm{H}_{2}\right)$ does not induce any reactivation of aluminum adsorbates ${ }^{50,54}$.

For all these reasons, PEALD seems to be a suitable technique to meet most devicescaling requirements. However, non-conformal thin film deposition in very high aspect ratio 3D structures (more than 20 for metal deposition and 100 for oxide deposition) remains a challenging problem for implementing PEALD potentiality for such purposes. This problem is associated with the inherent high reactivity of plasma radical species: because of their incomplete valence shell, they are very prompt to promptly recombine on $3 \mathrm{D}$ feature sidewalls, which automatically reduces their flux in the bottom of the $3 \mathrm{D}$ structure ${ }^{55}$. This problem has already been encountered in advanced interconnect applications, and the insertion of an $\mathrm{Ar}^{+}$plasma sputtering step in a HDP-CVD process to prevent clogging of 3D feature openings (known as bevelling step) is now considered as a viable solution to facilitate precursor deposition in the bottom of trenches and avoid the formation of voids during deposition $^{56}$. In regards to the knowledge gained from HDP-CVD process developments, it seems controversial that most common PEALD reactors are conceived with the consensus that a significant flux of neutrals and radicals species should be produced at the detriment of an energetic plasma ion flux, which should by any means be mitigated to prevent plasmainduced defects related to ion bombardment. The prevailing argument in favor of this consensus relies on the self-limited character of ALD chemical reactions that incident energetic plasma ions can possibly affect, thus deteriorating the key conformity asset of a PEALD process.

Ion flux in PEALD reactors can be monitored by varying experimental parameters such as pressure, gas flow rates and plasma source power within the chamber, whereas ion dose is usually reduced by a shorter duration of the plasma exposure step. The additional possibility to modulate the incident kinetic energy of plasma ion bombardment in PEALD processes has been investigated only recently in details. Taking advantage of ion bombardment during the plasma activation step of a PEALD deposition process is a quite recent innovation, which offers a very promising extension of standard PEALD. Indeed, it provides an additional degree of freedom for the definition of process conditions, which makes it possible to tune the physical properties of thin films at the nanometer scale, as discussed below. 
The case of $\mathrm{TiO}_{2}$ thin film was first investigated by Profijt et $a l^{57}$ who showed how the application of substrate biasing at low temperature induced fim crystallization. In 2015, Ratzsch et al $^{23}$ built a custom-made metallic grid placed above the substrate on which a positive DC bias voltage can be applied to decelerate plasma ions and prevent them from impinging on the substrate surface. With this set-up, they showed that a high positive bias voltage produced amorphous $\mathrm{TiO}_{2}$ thin films, whereas no applied bias lead to a microcrystalline structure. These observations indicate that plasma ions are responsible for the onset of $\mathrm{TiO}_{2}$ crystallite formation. A different experimental set-up was built by Ishawita et al in a capacitively coupled plasma reactor, by connecting an inductor on the substrate holder ${ }^{24}$. A variation of the overall reactance of the electric circuit allows the ion energy to be tuned. With this set-up, the authors also reported an alteration of $\mathrm{TiO}_{2}$ microstructural properties (density and refractive index) under high ion energy, as illustrated in Figure 6.

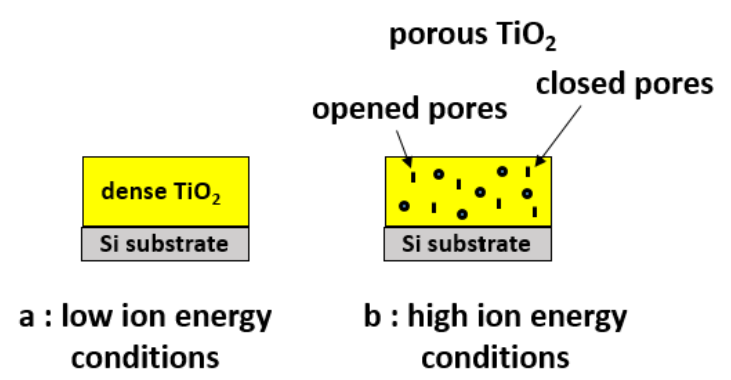

FIG. 6. (Color online) Illustration of ion bombardment impact on microstructure of $\mathrm{TiO}_{2}$ thin films. Adapted with permission from S. Iwashita, T. Moriya, T. Kikuchi, M. Kagaya, N. Noro, T. Hasegawa, and A. Uedono, J Vac. Sci. Technol. A 36, 021515 (2018), Copyright 2018 by the American Vacuum Society.

Extensive studies have been carried out by the group of W. M. M. Kessels from TU Eindhoven on a wide range of thin film materials to investigate the evolution of their physical properties with varying plasma ion energies in PEALD processes ${ }^{25-28}$. For this purpose, a radio-frequency RF biasing voltage is applied on the back-side of the chuck, to induce a selfpolarized negative DC voltage at the substrate surface, as described in details in ${ }^{29}$. This waveform biasing set-up contributes to enhance the potential drop in the plasma sheath that spontaneously forms in the vicinity of the substrate. This in turn allows the extraction of plasma ions impinging on the thin film under growth, with a tunable incident kinetic energy.

Experimental results show that thin film physical properties, such as microstructure, density, resistivity, residual stress, surface roughness and refractive index can be significantly 
altered when biasing the substrate during the plasma step of the PEALD cycle ${ }^{25-28}$. However, the trend in the evolution of these properties with increasing ion bombardment energy is specific to the materials at stake, as well as on the energy of the ion bombardment itself. Although no systematic conclusion can be drawn from these studies, published data clearly indicate that ion bombardment assistance during plasma exposure can become a valuable experimental knob in the PEALD tool, to enable fabrication of nanoscale thin films with adequate physical properties. In the following, the emblematic example of TiN thin films prepared under varying bias voltages is presented in details and discussed, as an illustration of the extended possibilities offered by ion bombardment during PEALD.

Figure 7 shows the variations in the Growth Per Cycle (GPC), resistivity, density, residual stress and surface roughness with corresponding Grazing Incidence X-Ray Diffraction (GIXRD) patterns for TiN thin films deposited at $200^{\circ} \mathrm{C}$ by PEALD with TDMAT Titanium precursor and $\mathrm{Ar} / \mathrm{H}_{2}$ plasma, as a function of applied voltage varying in the range from 0 to $-255 \mathrm{~V}$, as published in ${ }^{25}$. As underlined by the authors, as deposited PEALD TiN thin films exhibit up to 35 atomic percent $\mathrm{H}$ and $\mathrm{O}$ impurities confirmed by RBS data, accounting for the relatively high resistivity value, along with a low tensile residual stress, in agreement with already published data. The corresponding grazing incidence X-ray diffraction pattern exhibits small peak intensities with relatively broad widths, consistent with small crystalline grains, as revealed by TEM pictures, which also confirm a loosely packed microstructure, compatible with the low TiN density.

The application of a substrate bias is observed to have a substantial impact on the physical properties of TiN thin films. For bias voltages less than $-130 \mathrm{~V}$, a simultaneous decrease in the GPC and in the resistivity is measured, in parallel with an increase in the TiN thin film density. These trends match with a large reduction of $\mathrm{H}$ and $\mathrm{O}$ impurities (confirmed by RBS measurements), along with an improved TiN stoichiometry. Moreover, the residual stress evolves from tensile to compressive with applied bias voltage, with a maximum value reached at $-130 \mathrm{~V}$, attributed to larger grain size along with a reduction of voids, as evidenced by TEM analyses. These observations are also consistent with the narrowing of the peak linewidths in the X-ray diffraction pattern at $-87 \mathrm{~V}$ bias voltage, although a broadening is again observed at $-130 \mathrm{~V}$. This last point is attributed by the authors to the excessively high compressive stress within the TiN film, which contributes to diffraction peak broadening. 

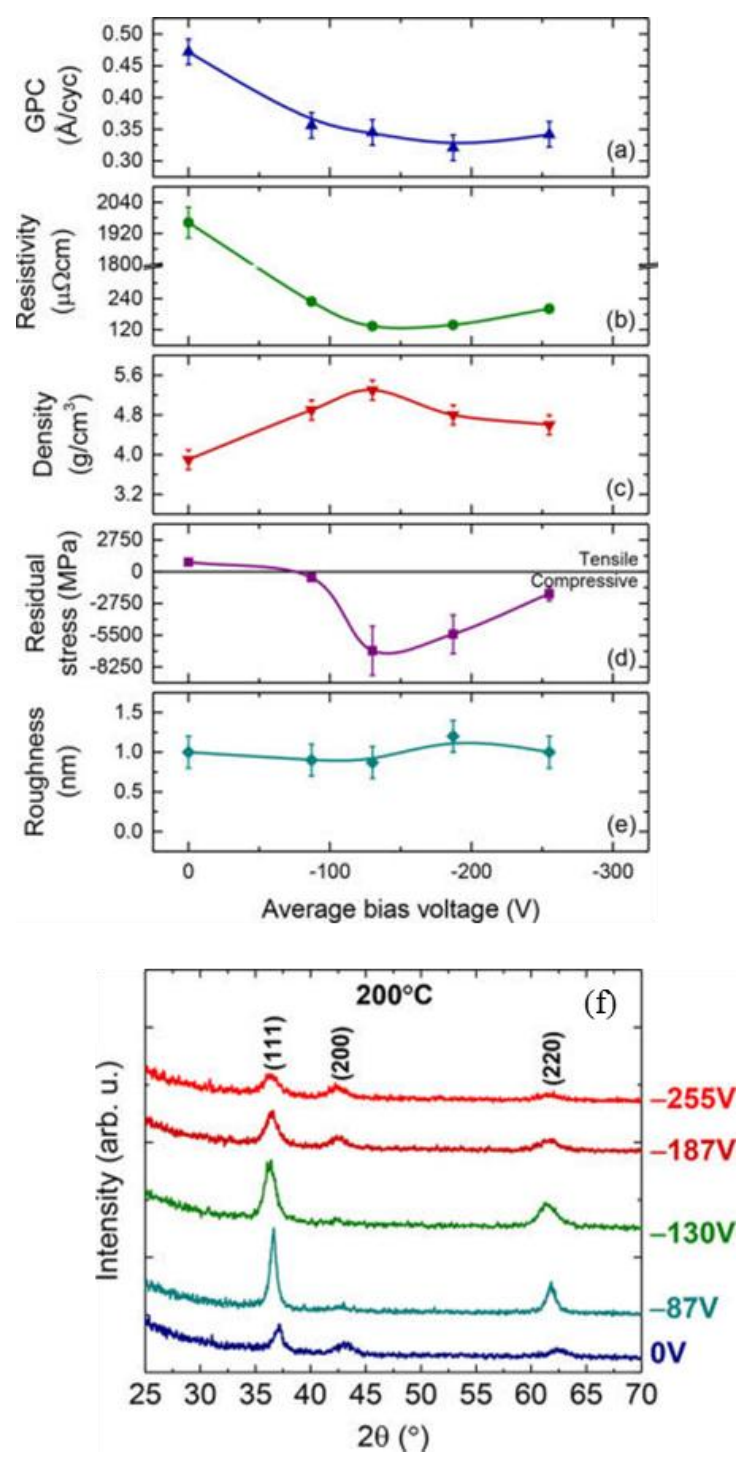

FIG. 7. (Color online) (a) Growth per cycle (GPC), (b)resistivity, (c) density, (d) residual stress and (e) RMS surface roughness of PEALD TiN thin films deposited at $200^{\circ} \mathrm{C}$, as a function of average bias voltage (0 to $-255 \mathrm{~V})$ applied during the $\mathrm{H}_{2} / \mathrm{Ar}$ plasma step, (f) Grazing incidence X-ray diffraction patterns of TiN films deposited at $200^{\circ} \mathrm{C}$ with indicated bias voltage applied during the $\mathrm{H}_{2} /$ Ar plasma step. Reprinted from T. Faraz, et al, ACS Appl. Mater. Interfaces 10, 13158 (2018), https://pubs.acs.org/doi/abs/10.1021/acsami.8b00183, with the permission of ACS (further permissions related to the material excerpted should be directed to the ACS).

When the bias voltage is further increased beyond $-130 \mathrm{~V}$, the overall impurity level is reported to increase significantly, mainly attributed to $\mathrm{C}$ and $\mathrm{Ar}$ incorporation in the film. This in turn explains the slight increase in TiN resistivity and decrease in mass density of the film that was attributed by authors ${ }^{25}$ to an increase in impurity content and an increase in the film 
void content. Under similar bias voltage conditions, the X-ray diffraction pattern collapses indicating a gradual amorphization, which can thus also account for the observed stress relaxation.

To complete the results on TiN from T. Faraz et $a l^{25}$, it is worth mentioning that our group has observed that the application of a heavy ionic bombardment $\left(\mathrm{V}_{\text {bias }}=-310 \mathrm{~V}\right)$ applied during the $15 \mathrm{sec} . \mathrm{N}_{2} / \mathrm{H}_{2}$ plasma step of our PEALD process can also drill through the TiN layer. This alters the substrate state below, and hence the interface quality, through the possible formation of nitrogen and hydrogen bubbles potentially increasing the residual stress, and/or a growing intermediate layer as well, to compensate for this increase. Figure 8 shows TEM pictures of PEALD TiN thin films prepared under no bias and heavy bias conditions using the PEALD Flexal tool from Oxford Instruments equipped with a RF biasing of the substrate (see reference from A. Chaker et al ${ }^{58}$ for more details on the tool). It shows the emergence of a $5 \mathrm{~nm}$ thick amorphous $\mathrm{SiON}$ interface with a deteriorated interface quality with respect to the silicon substrate under heavy ionic bombardment. This may in turn affect the microstructure of the TiN layer, as will be discussed elsewhere ${ }^{59}$.

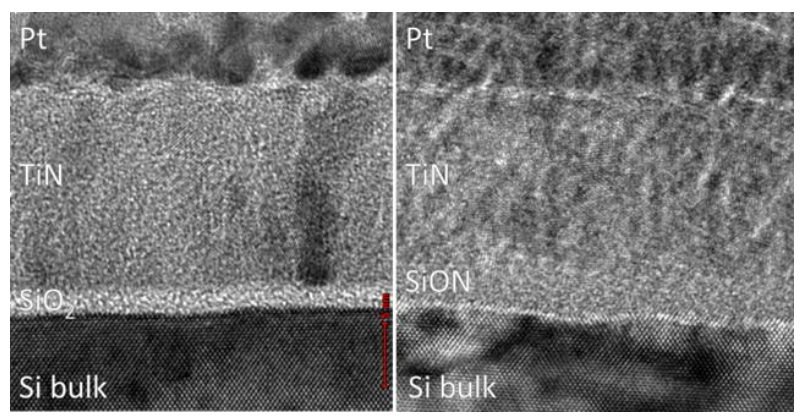

FIG. 8. TEM images showing the impact of a heavy bias on the interface quality of TiN PEALD thin films prepared on a Si substrate showing the emergence of a $5 \mathrm{~nm}$ SiON interfacial layer. Left: no bias applied; right: $-310 \mathrm{~V}$ bias applied during the $15 \sec \mathrm{N}_{2} / \mathrm{H}_{2}$ plasma step.

This brief overview shows that ion bombardment through substrate biasing in PEALD processes can have remarkable impact on the physical properties of the thin film under growth. The two stage dependence of TiN thin film physical properties with applied voltage points toward the existence of a threshold voltage inducing either a soft or a high energetic ion bombardment in the thin film under growth. On the one hand, at relatively low ion bombardment energies, ions reaching the surface can potentially stimulate surface reactions such as ligand desorption or migration of adatoms, thanks to their momentum transfer which 
converts into a limited thermal energy provided to the substrate. This can contribute to enhance the density, prevent void formation, drive larger grain formation and improve the purity and the crystallinity of the produced thin film. However, mechanisms such as sputtering or ion implantation require larger activation energies and for this reason remain insignificant at low ion bombardment energies. It is an interesting point for process optimization that such a soft energetic ion bombardment can then lead to enhanced thin film quality without any noticeable damaging effects.

On the other hand, when the bias voltage becomes larger, the high incident kinetic energy of plasma ions creates an atomic peening effect on the substrate surface, which possibly leads to both local thermal spikes and knock-on implantation of plasma ionic species with collision cascades below the surface of the material ${ }^{60}$. These phenomena give rise to localized defects, such as voids, pores and atomic disorder, which can extend up to a complete amorphization under heavy energetic ionic bombardment. The thermal spikes due to surface peening during ion bombardment can also afford for high local temperatures analogous to a local rapid thermal anneal capable of inducing in situ recrystallization of amorphous PEALD thin films. Indeed, our team has observed that a $-300 \mathrm{~V}, 10 \mathrm{sec}$ bias voltage applied during the PEALD $\mathrm{HfO}_{2} 10 \mathrm{~nm}$ thin film growth induces partial recrystallization evidenced by GIXRD measurements. These results will be published in a subsequent paper ${ }^{59}$.

In view of these proposed mechanisms, it appears that a long exposure to the plasma step without any applied bias voltage in PEALD processes essentially remains not totally efficient to improve overall thin film purity, because the ion flux impinging on the substrate surface is too low, and also has a low energy value, typically less than $30 \mathrm{eV}$ in ICP reactors ${ }^{61}$. This explains the relatively high resistivity value obtained in as-deposited PEALD TiN thin films: in spite of the high reactivity of plasma radical species, $\mathrm{O}$ and $\mathrm{H}$ related impurities cannot be all eliminated during the plasma step. However, the application of a $-87 \mathrm{~V}$ bias voltage during the plasma step creates a synergetic effect boosting momentum transfer and chemical reactivity among plasma species, making them more inclined to react with surface trapped impurities, favoring their desorption and evacuation via the pumping system. Thus, this synergetic effect accounts for the improved density and resistivity of TiN thin films prepared under low energy ion bombardment conditions.

From this, we can conclude that ion assistance in PEALD processes actually relies on a combination of two key parameters that determine its efficiency: the voltage bias itself, which defines the ion bombardment energy, and the ion dose, which corresponds to the duration of the ion flux exposure during the plasma step. Although adjusting these two 
parameters can be carried out independently from the plasma source, it produces a synergy within the plasma phase interacting with the substrate, which helps improve the thin film quality. Each materials undergoing growth requires a specific adjustment of its ion assistance parameters, in order to tailor its physical properties, and without such specific adjustment, detrimental plasma-induced defects may be promoted instead. As mentioned in the work of T. Faraz et al $^{25}$, the synergetic effect existing between radicals and ionic plasma species leads to complex interactions which may all come into play during thin film PEALD synthesis.

The obtained results demonstrate that substrate biasing is a promising technique to contrive thin films with specific physical properties by PEALD. In the following, we will discuss the benefits of using substrate biasing during PEALD to monitor the nucleation delay of the growth process. These two points are indeed of great interest for the development of selective deposition processes.

\section{Selective deposition process: ions versus radicals}

Area Selective deposition by ALD is new bottom up approach firstly developed to overcome strong critical patterning issues such as Edge Placement Error and related expanding costs ${ }^{62-64}$ and also used for catalysts design ${ }^{65}$. As illustrated in Figure 10, a selective deposition process would allow control of thin film growth along the three directions of space.

The area selective deposition process can differ as function of the targeted selectivity as illustrated in Table 3. This can be a surface chemistry-based selective process, or a topographically selective process (deposition in one direction and not the other). Finally, one can also want different properties for a unique material (resistivity, transparency), or varying chemical and/or structural composition (crystallinity, density, roughness, doping level) as a function of a surface or a space direction. 


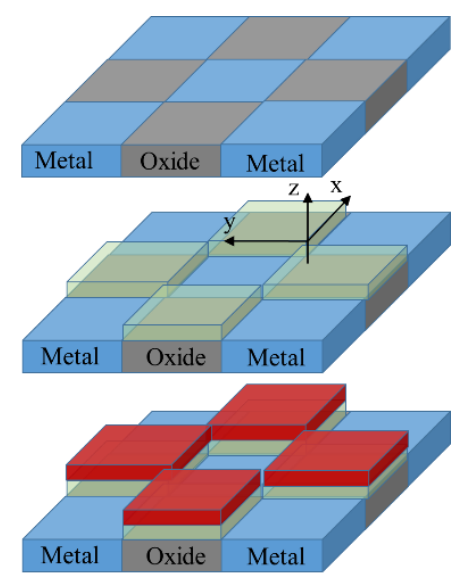

FIG. 9. (Color online) Illustration of an area selective deposition process (chemically-selective process)

Selective deposition by ALD can be obtained using: inherent selectivity of the process ${ }^{66-70}$, surface activation ${ }^{71}$, surface deactivation ${ }^{72-80}$, and super-cycles ABC type ${ }^{81}$ or with alternate deposition and etching steps ${ }^{58,82-85}$. As in PECVD and PEALD processes, ions from the plasma can be used in any of these steps and therefore help to promote a selective deposition. Several examples will be given in the following.

\begin{tabular}{|c|c|c|}
\hline Selective Process & Definition & Example \\
\hline $\begin{array}{c}\text { Area Selective } \\
\text { Deposition } \\
\text { (chemically selective } \\
\text { deposition) }\end{array}$ & $\begin{array}{l}\text { Deposition on chemically } \\
\text { selected surfaces and not } \\
\text { others }\end{array}$ & \\
\hline $\begin{array}{c}\text { Topographically } \\
\text { Selective Deposition }\end{array}$ & $\begin{array}{c}\text { Deposition in a pre- } \\
\text { determined space direction } \\
\text { only }\end{array}$ & \\
\hline $\begin{array}{l}\text { Chemical / Structural } \\
\text { Selective Deposition }\end{array}$ & $\begin{array}{l}\text { Different compositions or } \\
\text { structures on one desired } \\
\text { surface or space direction }\end{array}$ & 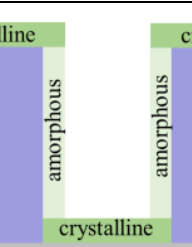 \\
\hline $\begin{array}{c}\text { Properties Selective } \\
\text { Deposition }\end{array}$ & $\begin{array}{l}\text { Different material } \\
\text { properties on one desired } \\
\text { surface or space direction }\end{array}$ & Oxide \\
\hline
\end{tabular}


Table 3. (Color online) Definitions and illustrations of different selective deposition processes

\subsection{Ions for inherent selectivity}

It has been shown previously in paragraph III that ions in a PEALD process can modify the GPC and film properties. In the work of T. Faraz et al ${ }^{25-28}$, an increase of GPC is observed for $\mathrm{HfO}_{2}, \mathrm{TiO}_{2}$ and $\mathrm{HfN}$ with ion energy, while a decrease of GPC was observed for $\mathrm{TiN}$ and $\mathrm{SiO}_{2}$. S. Iwashita et al ${ }^{24}$ also observed an increase of GPC for $\mathrm{TiO}_{2}$ when increasing ion energy during the PEALD process. However, no attention was devoted to the growth behavior during the initial cycles of the PEALD. The question is: is it possible that ion assistance can modify the inherent selectivity and increase or decrease the nucleation delay? This point is discussed below.

Figure 10 illustrates the initial growth behavior of TiN thin films prepared on Si-based substrates by PEALD under several biasing voltage values. The PEALD is carried out in a Flexal tool from Oxford Instruments, equipped with a substrate biasing system operating at 13.56 MHz RF power ${ }^{58}$. The conventional PEALD process consists of pulses of TDMAT followed by pulses of $\mathrm{N}_{2} / \mathrm{H}_{2}$ plasma separated with $\mathrm{Ar}$ purges. As can be seen in Figure 10a, the growth is quasi-linear without any substrate bias (that is to say with limited ions assistance), with a GPC of $0.7 \AA$ A/cycle. No nucleation delay is observed. However, when biasing the substrate during the PEALD process (that is to say: when adding energetic nitrogen and hydrogen ions to the PEALD process), a nucleation delay is observed at moderate energies without any significant changes in the GPC. At higher energy (DC selfbias voltage of $-302 \mathrm{~V}$ ), an important nucleation delay is observed, along with a decrease in the GPC. With such high bias voltage, up to 40 cycles nucleation delay can be obtained. Figure 10b shows that tuning the plasma duration can thus also favor the onset of this nucleation delay.
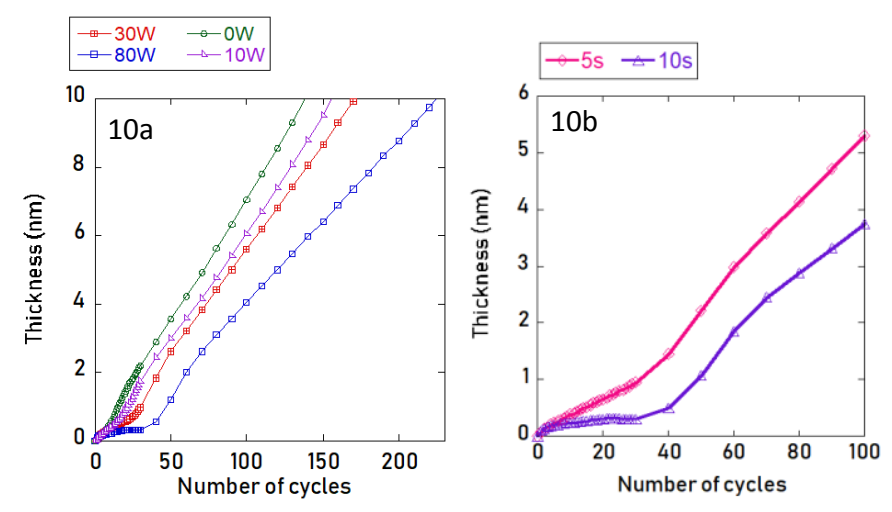
FIG. 10. (Color online) Nucleation delay modification by adding energetic ions during the plama step of TiN thin films prepared by PEALD. Figure 10a shows the impact of ion energy on the deposited thickness as a function of cycle number, by in situ ellipsometry; Figure 10b shows the impact of the energetic plasma duration time (i.e. ion dose)

It can be concluded, based on this example, that controlling the ion energy through substrate biasing in a PEALD process enables an Area Selective Deposition (ASD) process thanks to an induced nucleation delay.

In addition, modulating the ion energy should also help the selective deposition on $3 \mathrm{D}$ structures (topographically selective deposition), since the deposition on top and bottom of 3D structures can be strongly limited because energetic incident ions will sputter-clean these surfaces, whereas the growth readily starts without any delay on sidewalls which are not exposed to the energetic ion bombardment. The use of ions in 3D structures for "activation" or "deactivation" of the growth on selected surfaces will now be discussed.

\subsection{Ions for surface activation or surface deactivation}

In ALD processes, two steps can limit/favor the deposition (see illustration in Table 4):

- Step 1: the precursor/surface interaction

- Step 2: the precursor/co-reactant interaction

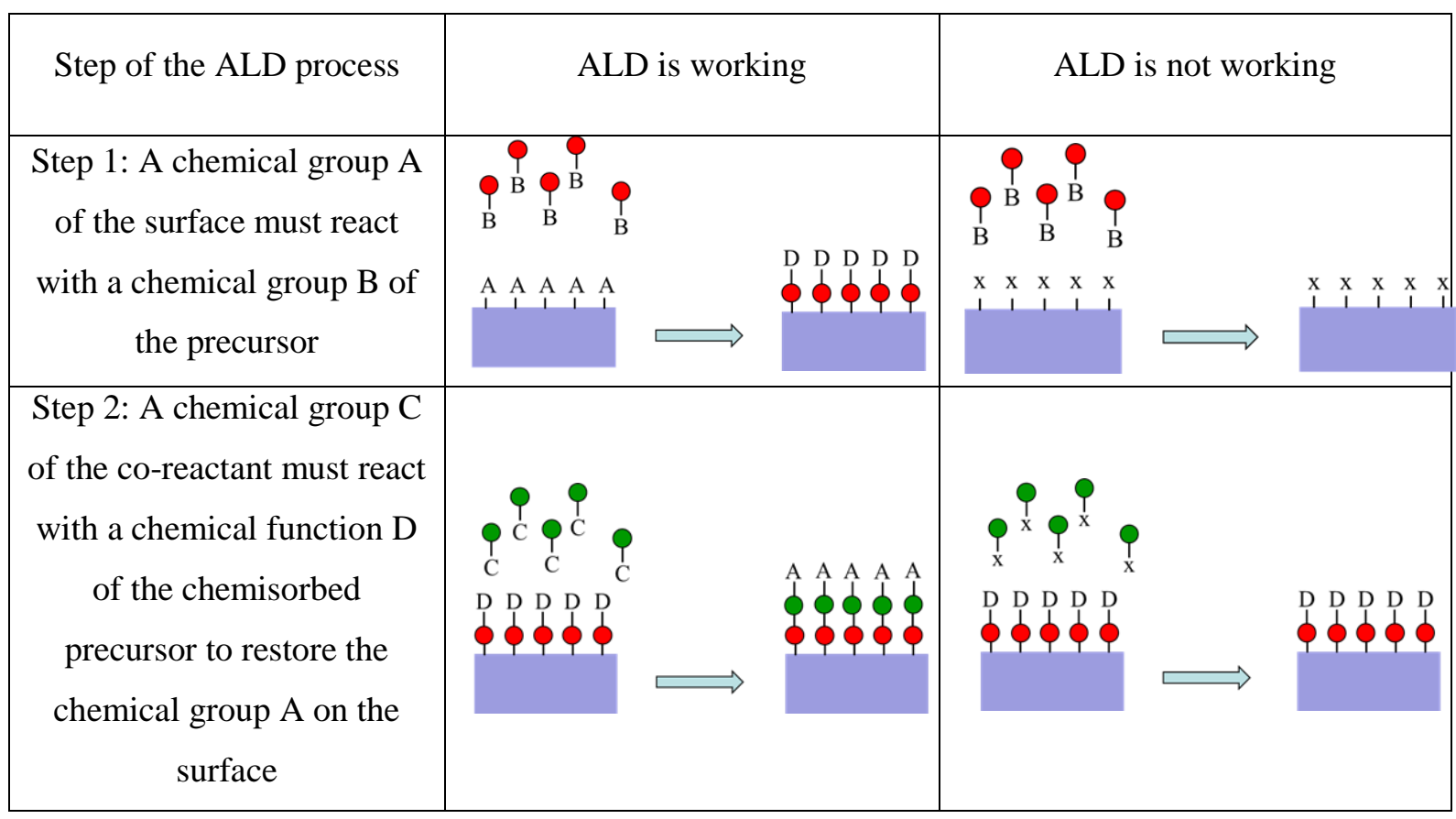

Table 4. (Color online) Illustration of the two ALD steps 
In case of a collisionless sheath, ions from the plasma are impinging perpendicular to the surface, due to the constant DC voltages applied to the substrate (grounded, floating voltage or biasing voltage). Therefore, they can be efficiently used in 3D selective processes in order to modify the chemistry of the surface during step 1 or step 2 , and then modify the occurrence of the corresponding chemical reaction, as illustrated in Table 5 for the step 1 of table 4 .

The case of TiN deposition under ion bombardment shown in paragraph IV.1 is an illustration of this. With ion assistance, nearly 50 cycles of nucleation delay can be achieved. These 50 cycles correspond to a thickness of $3.5 \mathrm{~nm}$ of TiN thickness deposited without ion bombardment (with a GPC of $0.7 \AA$ Acycle). As a consequence, a topographically selective deposition can be obtained when using this process on 3D features in Si substrates, as illustrated in Figure 11. The selective sidewall thickness can be as important as the nucleation delay created of surfaces exposed to the ion flux.

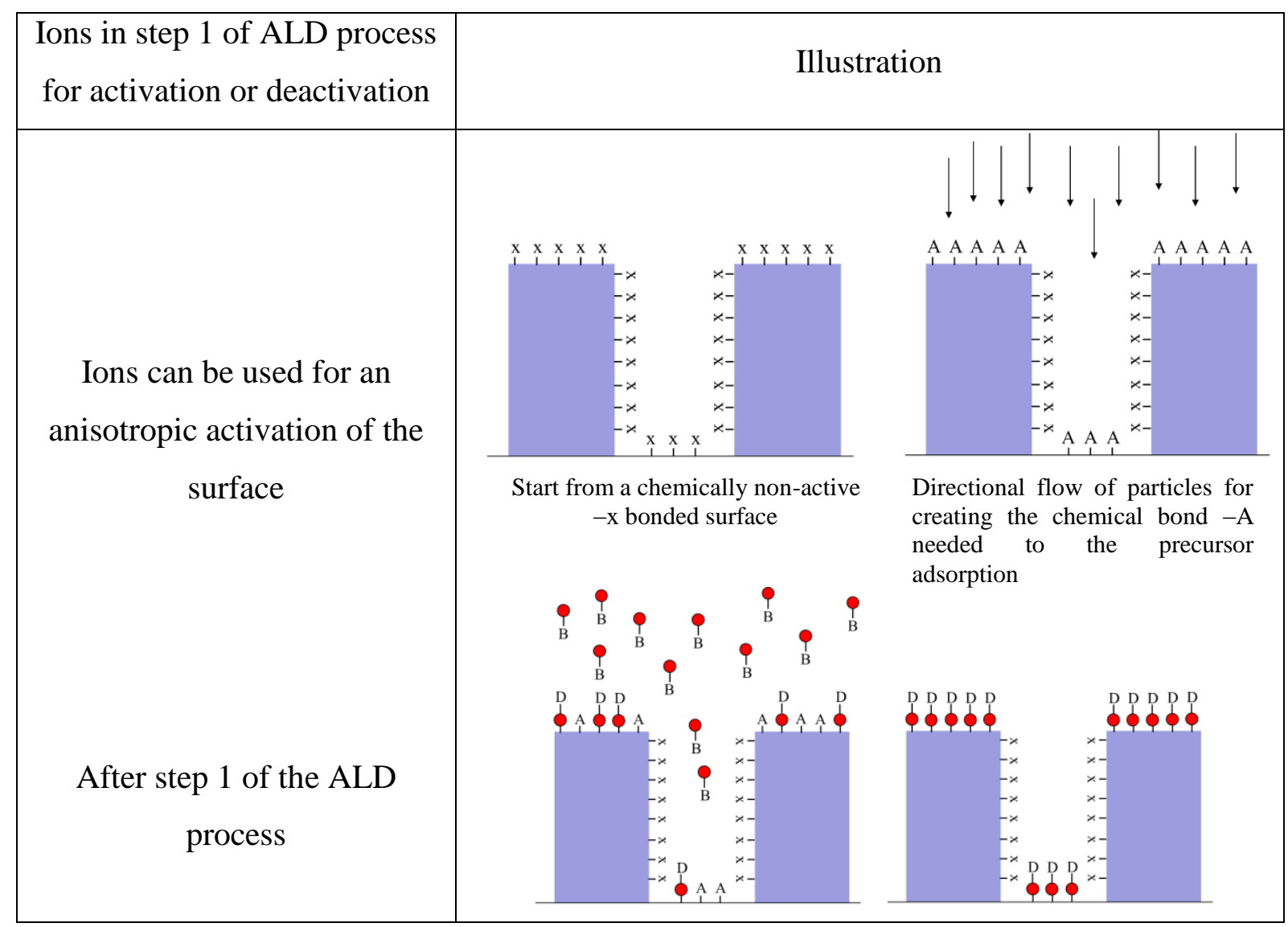




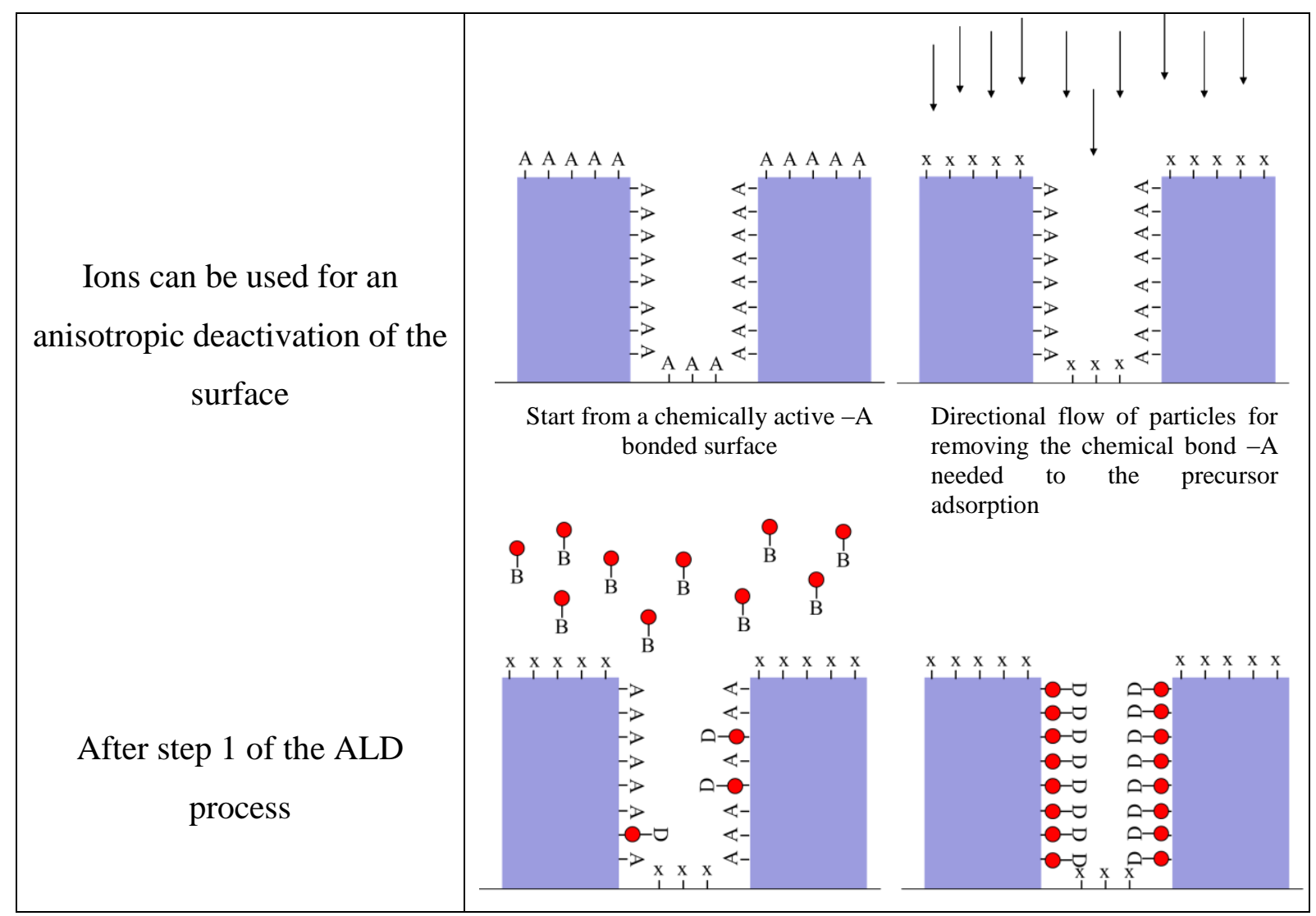

Table 5. (Color online) Illustration of surface activation or deactivation by ions

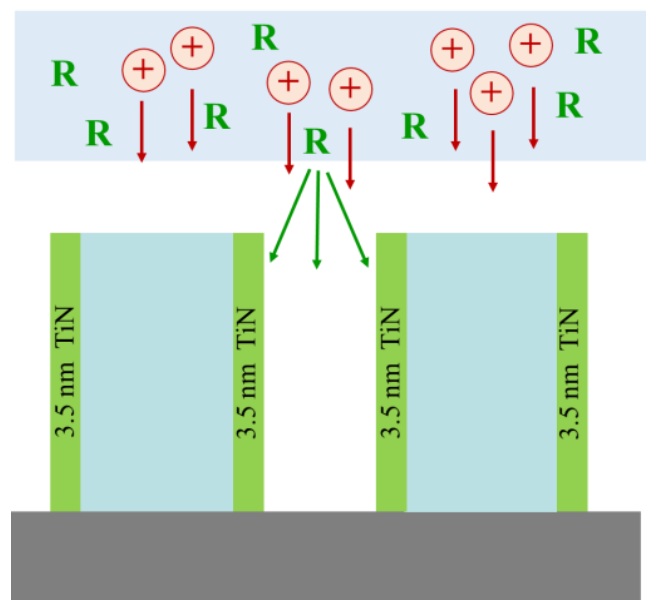

FIG. 11. (Color online) Topographically selective deposition of TiN on 3D features thanks to the nucleation delay (surface deactivation) induced by the vertically energetic ions bombardment

A second example of anisotropic deactivation of the surface for step 1 based on ions can be found in the work of W.H. Kim et $\mathrm{al}^{86}$. In their work, they used $\mathrm{CF}_{\mathrm{X}}{ }^{+}$ions from a $\mathrm{CF}_{4}$ plasma discharge before the ALD process. With this prior plasma step, the top and bottom of a 3D feature was chemically modified by $\mathrm{CF}_{\mathrm{x}}^{+}$ion implantation (see illustration Figure 12). 
During the subsequent ALD process, the Pt precursor adsorption was blocked on fluorinated surfaces, giving rise to a topographically selective deposition of $\mathrm{Pt}$ on sidewalls only, as illustrated in Figure 12.

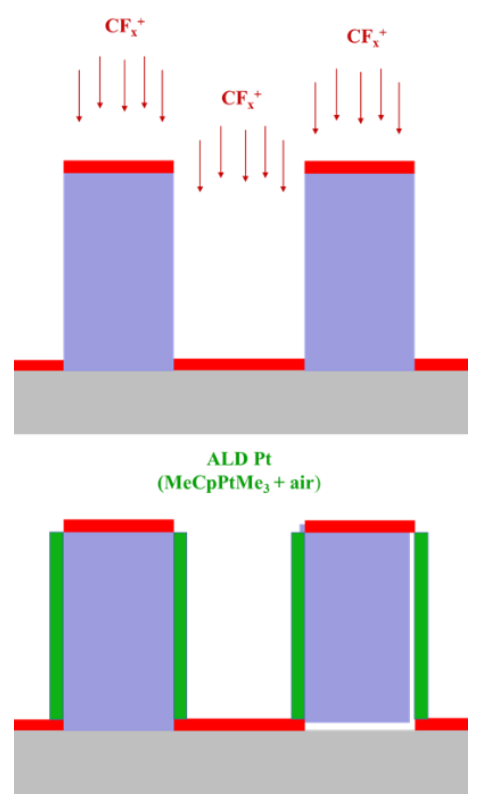

FIG. 12. (Color online) Example of an anisotropic surface deactivation by $\mathrm{CF}_{\mathrm{x}}{ }^{+}$ions. Adapted with permission from W. H. Kim, F. S. M. Hashemi, A. J. M. Mackus, J. Singh, Y. Kim, D. Bobb-Semple, Y. Fan, T. Kaufman-Osborn, L. Godet, and S. F. Bent, ACS Nano 10, 4451 (2016), Copyright 2016 by the American Chemical Society

The anisotropic activation of a surface in step 1 of the ALD process has recently been demonstrated by J.K. Sprenger et al ${ }^{87-88}$ using not an incident ion flux but an electron flux instead. In their work, an electron flood gun was oriented perpendicular to the surface in order to locally activate a non-active $\mathrm{Si}-\mathrm{H}$ surface, by removing $\mathrm{H}$ atoms from the surface and create active Si dangling bonds, followed by disilane adsorption at room temperature, as illustrated in Figure 13.

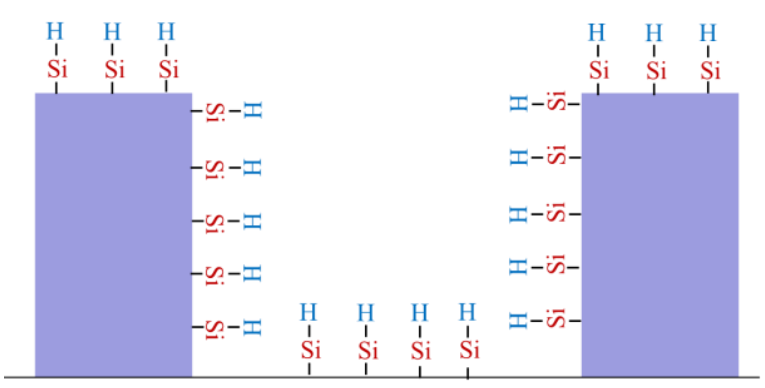



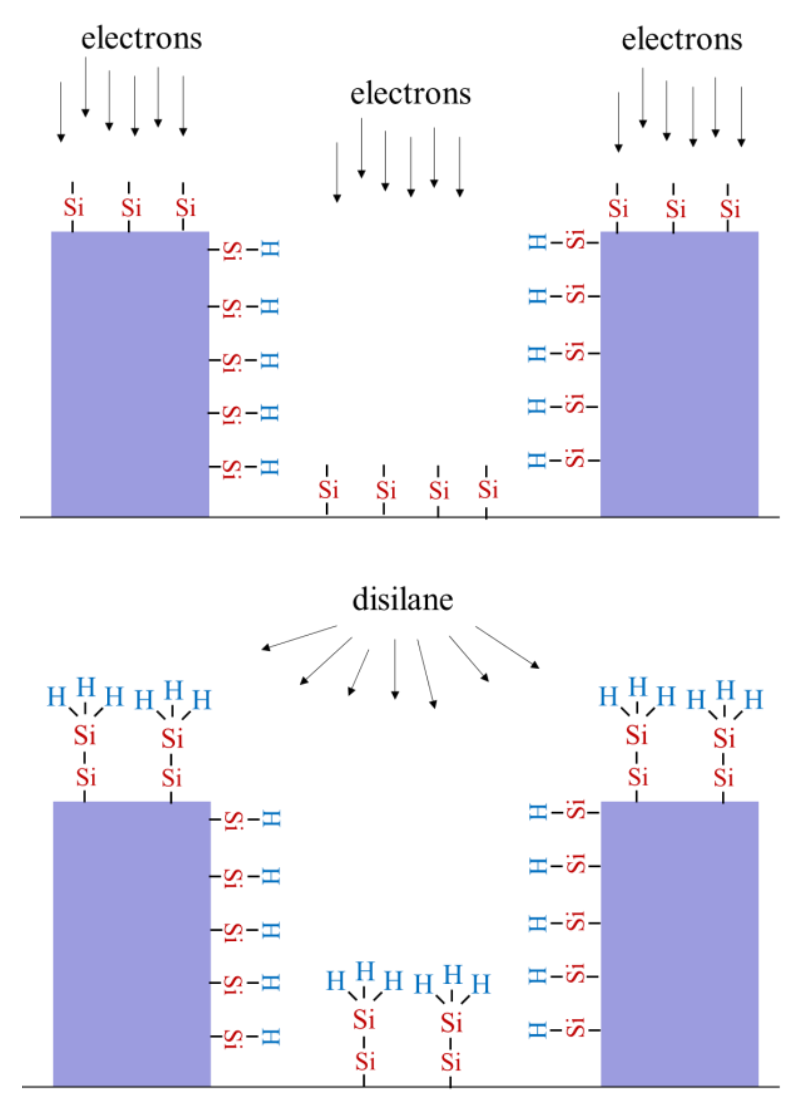

FIG. 13. (Color online) Example of an anisotropic surface activation by electron flood guns. Adapted with permission from J K. Sprenger, H. Sun, A.S. Cavanagh, and S. M. George, J. Vac. Sci. Technol. A36, 01A118 (2018), Copyright 2018 by the American Vacuum Society.

\section{3 ions for an anisotropic modification of material structure, composition or properties}

It has already been discussed in section III that ion assistance in a PEALD process can modify the deposited film properties (structural, electrical as well as optical) in terms of resistivity, refractive index, density as well as crystallinity. Therefore, the use of an anisotropic flow of energetic ions during a PEALD process may be useful for a property selective deposition on 3D features. A very nice example has been published by T. Faraz et al ${ }^{25}$ who used energetic ions during the PEALD of $\mathrm{TiO}_{2}$ on $3 \mathrm{D}$ substrates. As shown in Figure 14 , the addition of a $200 \mathrm{~V}$ bias to the substrate during the oxygen plasma step induces a $\mathrm{TiO}_{2}$ rutile phase on top and bottom of the structure, while the sidewalls not submitted to energetic ions were covered with an amorphous $\mathrm{TiO}_{2}$. The scientific discussion on the role of energetic ions in the phase change of $\mathrm{TiO}_{2}$ structure (from amorphous to anatase and then rutile) can be found in the paper from H. B. Profjit et $a l^{29}$ and T. Faraz et $a l^{25}$. 

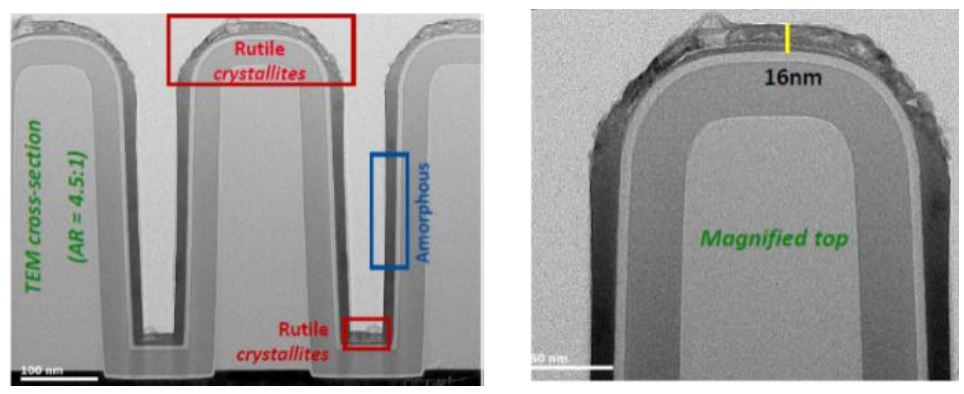

FIG. 14. (Color online) Cross-sectional TEM image of $\mathrm{TiO}_{2}$ deposited by PEALD on 3D trench structure using an average $\mathrm{DC}$ bias of $-205 \mathrm{~V}$ during $\mathrm{O}_{2}$ plasma. Reprinted from $\mathrm{T}$. Faraz, et al, ACS Appl. Mater. Interfaces 10, 13158 (2018),

https://pubs.acs.org/doi/abs/10.1021/acsami.8b00183, with the permission of ACS (further permissions related to the material excerpted should be directed to the ACS)

The topographic material modification thanks to ion assistance in a PEALD process can be used for topographically selective deposition by adding a selective chemical etching step after the deposition one. The basic idea is to use ions to modify topographically the film density or the film composition (in terms of impurity content) or the crystallinity of the film. The modified layer should exhibit a modified etch rate, enabling selective deposition. This is illustrated in Figures 15 and 16.

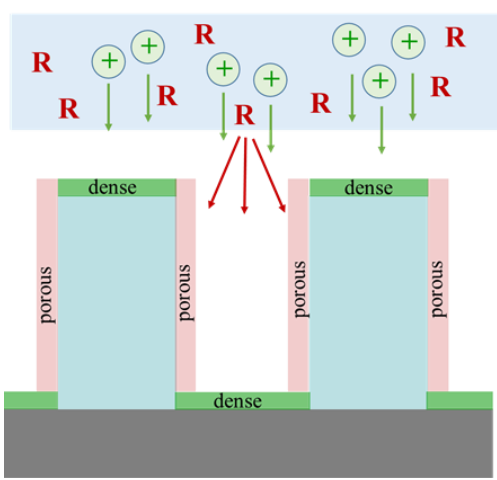

FIG. 15. (Color online) Selective deposition on top and bottom using a selective etching 
after the PEALD process with ion assistance. With this process, surfaces exposed to energetic ions give denser film.

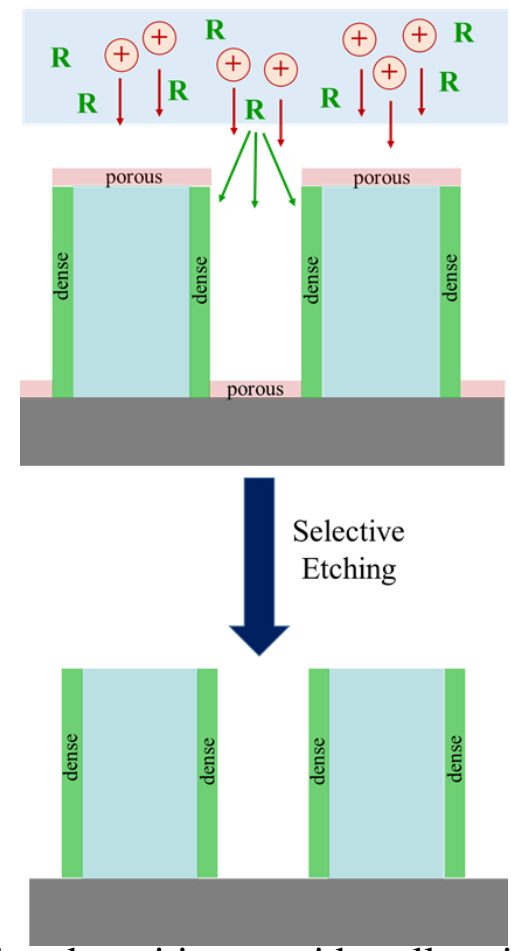

FIG. 16. (Color online) Selective deposition on sidewalls using a selective etching after the PEALD process with ion assistance. With this process, surfaces exposed to energetic ions give porous film.

Few examples can already be found in the literature illustrating the case of Figures 15 and 16. In Figure 17, T. Faraz et al ${ }^{25}$ used ion bombardment with a DC self-bias voltage of $-103 \mathrm{~V}$ during the $\mathrm{N}_{2}$ plasma of the PEALD process at $500^{\circ} \mathrm{C}$, in order to modify the density of a silicon nitride thin film. The use of energetic ion assistance during the PEALD process is evidenced by the facet formation on the top of the feature due to sputtering mechanisms. When exposed to a selective wet etching in a diluted hydrofluoric acid solution $\left(\mathrm{HF}: \mathrm{H}_{2} \mathrm{O}=1: 100\right)$, the thin film portion located at the top and bottom surfaces is completely removed, due to a very high wet etching rate (WER) compared to the very low WER of sidewalls surfaces. 


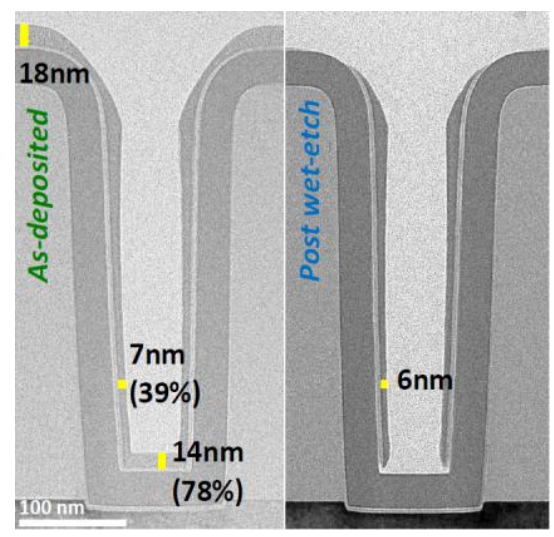

FIG. 17. (Color online) Topographically selective deposition at sidewalls using PEALD and ions followed by selective etching. Reprinted from T. Faraz, et al, ACS Appl. Mater. Interfaces 10, 13158 (2018), https://pubs.acs.org/doi/abs/10.1021/acsami.8b00183, with the permission of ACS (further permissions related to the material excerpted should be directed to the ACS).

A second example is given in the work of M. Hirayama et al ${ }^{89}$. In their work, they used a low-energy ion bombardment $(<15 \mathrm{eV})$ during the PEALD of $\mathrm{Al}_{2} \mathrm{O}_{3}$ on $\mathrm{Si}$ and $\mathrm{SiO}_{2}$ substrates. With the assistance of a high ion flux during deposition, a thick $\mathrm{AlSiO}_{\mathrm{x}}$ layer is formed when the deposition is made on $\mathrm{Si}$, whereas $\mathrm{Al}_{2} \mathrm{O}_{3}$ forms on $\mathrm{SiO}_{2}$. Then they proposed to use this layer modification $\left(\mathrm{AlSiO}_{\mathrm{x}}\right.$ versus $\left.\mathrm{Al}_{2} \mathrm{O}_{3}\right)$ for a selective deposition process, as illustrated in Figure 18.

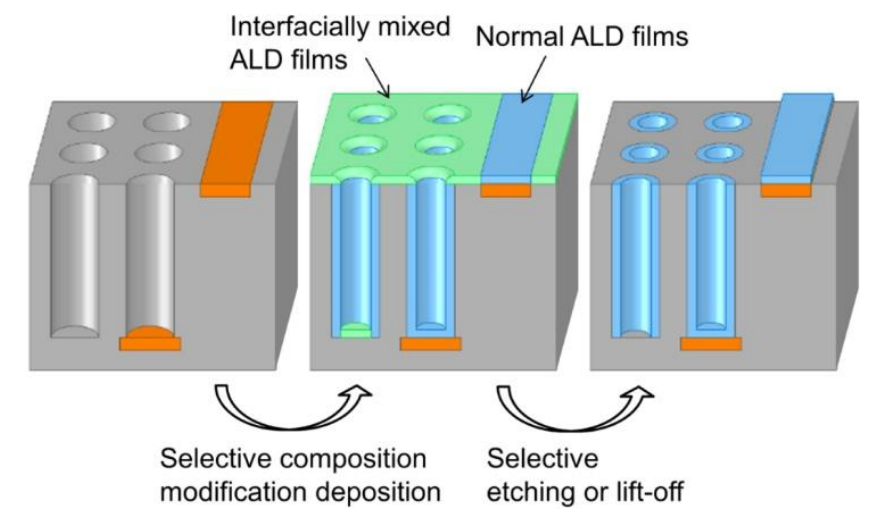

FIG. 18. (Color online) Selective deposition of $\mathrm{Al}_{2} \mathrm{O}_{3}$ by removing AlSiOx layers formed on Si surfaces exposed to ion bombardment, with a selective etching step. Reprinted with permission from M. Hirayama and S. Sugawa 2019 Jpn. J. Appl. Phys. 58 110902, Copyright (2019) the Japan Society of Applied Physics.

\section{4 ions for the deposition/etch approach}


One last approach for selective deposition is to exploit ions from the plasma for an in situ etching step during the PEALD process, so-called ASD by deposition/etching or supercycles (see some examples here ${ }^{58,82-85}$ ). The sidewall deposition illustrated in Figure 16 can be easily obtained without modifying the nature of the deposited film if an anisotropic etching cycle is added to the PEALD cycles, as shown Figure 19.
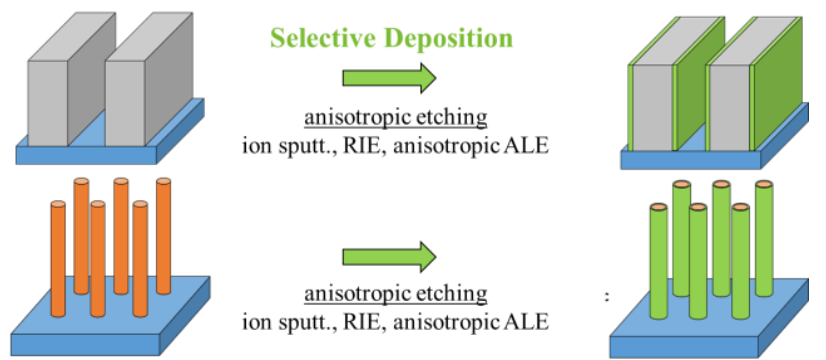

FIG. 19. (Color online) Illustration of a selective sidewalls deposition by combining super cycles of PEALD + anisotropic etching. Adapted from R. Vallat, R. Gassilloud, O. Salicio, K. El Hajjam, G. Molas, B. Pelissier, and C. Vallée, J. Vac. Sci Technol. A 37, 020918 (2019), Copyright 2018 by the American Vacuum Society.

A proof of concept has been demonstrated by A. Chaker et al ${ }^{58}$ for the topographically selective deposition of $\mathrm{Ta}_{2} \mathrm{O}_{5}$ on $3 \mathrm{D} \mathrm{Si}$ features, with several argon plasma steps with biasing assistance inserted in the PEALD cycles of $\mathrm{Ta}_{2} \mathrm{O}_{5}$ (TBTDMT $+\mathrm{O}_{2}$ plasma) (Figure 20). This work was made in a Flexal tool from Oxford Instruments with an additional RF biasing waveform applied to the substrate. After many process optimization steps, (experimental parameters: ion energy, plasma duration, number of super cycles), a selective sidewall deposition could successfully be obtained on 3D $\mu \mathrm{m}$-scaled patterned substrates having aspect ratios of 7 and 5 respectively (see A. Chaker et al ${ }^{58}$ ). This process has recently been tested on smaller 3D devices, as illustrated in Figure 21. The structural properties were characterized in cross section view by scanning transmission electron microscopy (STEM) based on a field-emission-gun (FEG) electron source across thin lamellas prepared with a FIB-SEM tool (helios NanoLab 450S from FEI) combining focused ion and electron beams. STEM images were directly realized under the SEM column at $30 \mathrm{keV}$ to get spatial resolution less than $1 \mathrm{~nm}$. The $\mathrm{Ta}_{2} \mathrm{O}_{5}$ deposition appears dark in both STEM images. This figure clearly shows that the selective deposition process leads to deposition on vertical surfaces only. 

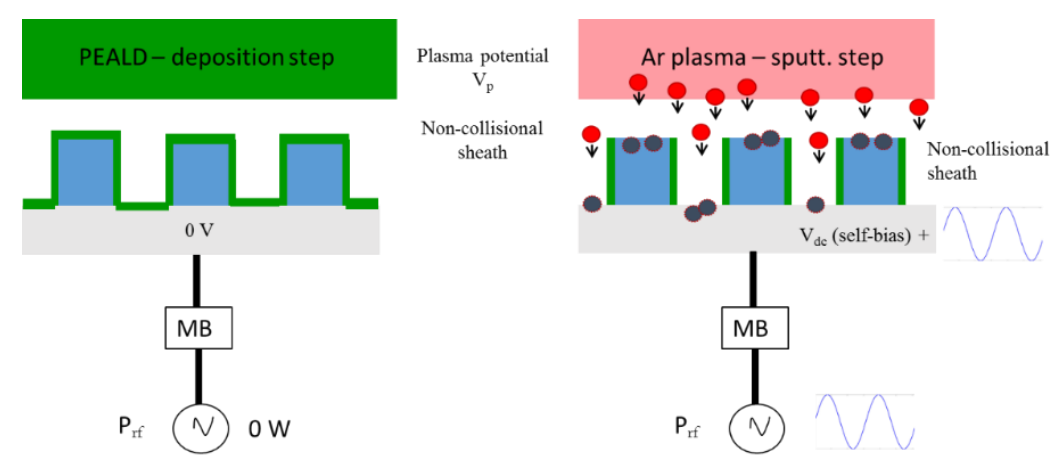

FIG. 20. (Color online) Illustration of the deposition/etch super-cycle used for sidewall selective deposition: the PEALD step is made without biasing the substrate ; for the argon etching step (anisotropic sputtering), a weak RF power is applied to the substrate in order to accelerate argon ions with low/moderate energies (more information can be found in ${ }^{58}$ )
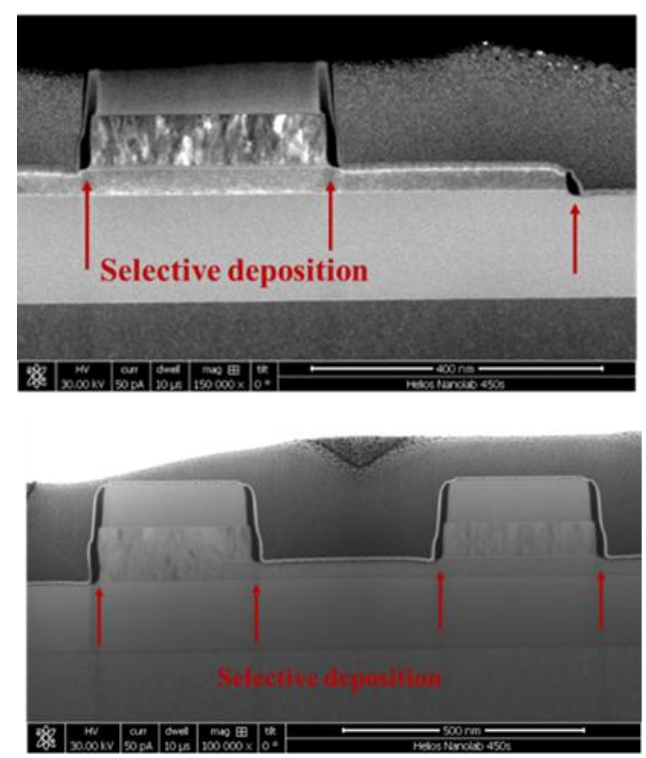

FIG. 21. (Color online) STEM Image of $\mathrm{Ta}_{2} \mathrm{O}_{5}$ selectively deposited on sidewalls using the super-cycles deposition/etch approach with anisotropic etching controlled by a flow of low energetic argon ions.

\section{CONCLUSION}

The increasing complexity of advanced CMOS technology nodes puts aggressive requirements on thin film processing where atomic scale thickness and physical property control are necessary for a very broad panel of materials. In this regard, the PEALD technology with its unique capabilities plays and will continue to play a key role in advanced thin film processing. We have shown that the implementation of substrate biasing enabling plasma ion extraction during a plasma-based chemistry deposition process (PECVD and 
PEALD) definitely brings a valuable add-on capability to PEALD processes. Indeed, ion energy tuning gives an additional degree of freedom to finely control the physical properties of the grown thin films, thanks to the synergetic effect between ions and radicals through momentum transfer and activated chemical interactions between the plasma gas phase and substrate surface, as shown forty years ago by Coburn and Winters for plasma etching. Impurity removal or incorporation, thin film densification or porosity incorporation, stress engineering, amorphization or crystallization can be readily achieved by tuning the ion energy. Such adaptable physical properties during materials deposition paves the way to large number of possibilities for the development of selective deposition processes, whether on planar substrates or in 3D structures. In this sense, further atomic scale process developments assisted by ionic bombardment have a bright future ahead.

\section{Acknowledgements}

This work was supported by the H2020 European project WAKE ME UP n ${ }^{\circ} 783176$ 


\section{REFERENCES (1 à 18 partie PECVD)}

${ }^{1}$ J. W. Coburn and Harold F. Winters, J. Vac. Sci. Technol. A 16, 391 (1979)

${ }^{2}$ J. W. Coburn and Harold F. Winters, J. Appl. Phys. 50, 3189 (1979)

${ }^{3}$ J. R. Webster, C. W. Dyck, C. D. Nordquist, J. A. Felix, M.R. Shaneyfelt, J. R. Schwank, and J.C. Banks, 2005 IEEE International Reliability Physics Symposium, 2005. Proceedings. 43rd Annual., San Jose, CA, USA, 330-336 (2005)

${ }^{4}$ K-M. Chang, W-C. Yang and C-P. Tsai, IEEE Transactions on Electron Devices 51 (1), 63 (2004)

${ }^{5}$ Alan K. Fritz and Leonard J. Olmer, IEEE Transactions on Semiconductor Manufacturing 30 (4), $426(2017)$

${ }^{6}$ H. Miyajima, K. Ishikawa, M. Sekine, and M. Hori, Plasma Process Polym. 16 (9) (2019)

${ }^{7}$ H C Shiny and C. Hu, Semicond. Sci. Technol. 11, 463 (1996)

${ }^{8}$ A. H. M. Smets, W. M. M. Kessels, and M. C. M. van de Sanden, J. Apply. Phys. 102, 073523 (2007) ${ }^{9}$ A. Michelmore1, J. D. Whittle, and R.D. Short, Front. Phys. 3, 1 (2015)

${ }^{10}$ B. Kim, and S. Kim, Journal of the Korean Physical Society 54, 1187 (2009)

${ }^{11}$ R.G. Andosca, W. J. Varhue, and E. Adams, J. Appl. Phys. 72, 1126 (1992)

${ }^{12}$ L. Martinu, and D. Poitras, J. Vac. Sci. Technol. A 18, 2619 (2000)

${ }^{13}$ L. Martinu, J.E. Klemberg-Sapehia, O.M. Küttel, A. Ravel, and M.R. Wertheimer, J. Vac. Sci. Technol. A 12, 1360-1364 (1994)

${ }^{14}$ J.C. Angus, P. Koidl, S. Domitz, in: J. Mort, F. Jansen (Eds.), Plasma Deposited Thin Films, CRC Press, Boca Raton, (1986)

${ }^{15}$ J. Robertson, Surf. Coat. Technol. 50, 185 (1992) 185

${ }^{16}$ B. Kalache, A.I. Kosarev, R. Vanderhaghen, and P. Roca i Cabarrocas, Journal of NonCrystalline Solids 299-302, 63 (2002)

${ }^{17}$ D. Goghero, A. Goullet, G. Borvon, and G. Turban, Thin Solid Films 471, 123 (2005)

${ }^{18}$ A. Durandet, and D. R. McKenzie, J. Appl. Phys. 80, 4707 (1996)

${ }^{19}$ O. Joubert, R. Burke, L. Vallier, C. Martinet, and R. A. B. Devine, Appl. Phys. Lett. 62, 228 (1993)

${ }^{20}$ K.L. Seaward, J. E. Turner, K. Nauka, and A. M. E. Nel, J. Vac. Sci. Technol. B 13, 118 (1995)

${ }^{21}$ S.C. Deshmukh and E.S. Aydil, J. Vac. Sci. Technol. A 13, 2355 (1995)

${ }^{22}$ S.M. Han and E.S. Aydil, J. Vac. Sci. Technol. A 14, 2062 (1996)

${ }^{23}$ S. Ratzsch, E. B. Kley, A. Tünnermann, and A. Szeghalmi, Materials 8, 7805 (2015) 
${ }^{24}$ S. Iwashita, T. Moriya, T. Kikuchi, M/ Kagaya, N. Noro, T. Hasegawa, and A. Uedono, J Vac. Sci. Technol. A 36, 021515 (2018)

${ }^{25}$ T. Faraz, H. C. M. Knoops, M. A. Verheijen, C. A. A. van Helvoirt, S. Karwal, A. Sharma, V. Beladiya, A. Szeghalmi, D. M. Hausmann, J. Henri, M. Creatore, and W. M. M. Kessels, ACS Appl. Mater. Interfaces 10, 13158 (2018)

${ }^{26}$ T. Faraz, M. van Drunen, H.C. M. Knoops, A. Mallikarjunan, I. Buchanan, D. M. Hausmann, J. Henri and W. M. M. Kessels, ACS Appl. Mater. Interfaces 9, 1858 (2017)

${ }^{27}$ T. Faraz, K. Arts, S. Karwal, H. C. M. Knoops, and W. M. M. Kessels, Plasma Sources Sci. Technol. 28, 024002 (2019)

${ }^{28}$ S. Karwal, M. A. Verheijen, B. L. Williams, T. Faraz, W. M. M. Kessels, and M. Creatore, J. Mater. Chem. C 6, 3917 (2018)

${ }^{29}$ H. B. Profijt, M. C. M. Van de Sanden, and W. M. M. Kessels, J. Vac. Sci. Technol. A 31, $01 \mathrm{~A} 106$ (2013)

${ }^{30}$ C. Cavallotti, M. Di Stanislo, and S. Carrà, Progress in Crystal growth and characterization of Materials 48/49, 123 (2004)

${ }^{31}$ H.R. Kaufman and J.M.E Harper, J. Vac. Sci. Technol. A 22, 221 (2004)

${ }^{32}$ A. von Keudell, Plasma Sources Sci. Technol. 9, $455(2000)^{33}$ D. Li, S. Elisabeth, A. Granier, M. Carette, A. Goullet, and J.P. Landesman, Plasma Process Polym. 13, 918 (2016)

${ }^{34}$ D. Li, S. Dai, A. Goullet, and A. Granier, Plasma Process Polym. 16, 1900034 (2019)

${ }^{35}$ F. Thièry, C. Vallée, Y. Arnal, and J. Pelletier, Surf. Coat. Technol. 186, 146 (2004)

${ }^{36}$ P. Reinke, W. Jacob, and W. Möller, J. Apply. Phys. 74, 1354 (1993)

${ }^{37}$ W. Jacob, Thin Solid Films 326, 1 (1998)

${ }^{38}$ T. Scwarz-Selinger, A. von Keudell, and W. Jacob, J. Appl. Phys. 86, 3988 (1999)

${ }^{39}$ K.G.Y. Letourneur, S.CM. Aerts, M.CM. Van de Sanden, D.C. Schram, Proceedings of the CIP'97, May 25-29 (Le Mans) France

${ }^{40}$ W.S. Tan, P.A. Houston, G. Hill, R.J. Airey, and P.J. Parbook, Journal of Electronic Materials 33, No 5 (2004)

${ }^{41}$ F Piallat, C Vallée, R Gassilloud, P Michallon, B Pelissier, and P Caubet, J. Phys. D: Appl. Phys. 47, 185201 (2014)

${ }^{42}$ P. D. Szkutnik, M. Aoukar, V. Todorova, L. Angélidès, B. Pelissier, D. Jourde, P. Michallon, C. Vallée, and P. Noé, J. Appl. Phys. 121, 105301 (2017)

${ }^{43}$ W.S. Yoo, R. Swope, and D. Mordo, Jpn. J. Appl. Phys. 36, 267 (1997)

${ }^{44}$ P. Noé, C.Vallée, F. Hippert, F. Fillot, and J-Y. Raty, Semicond. Sci. Technol. 33, 013002 (2018) 
${ }^{45}$ R.A. Ovanesyan, E.A. Filatova, S.D. Elliott, D.M. Hausmann, D.C. Smith, and S. Agarwal, J. Vac. Sci. Technol. A 37,060904 (2019)

${ }^{46}$ C. Detavernier, J. Dendooven, D. Deduytsche, and J. Musschoot. ECS Trans. 16, 239 (2008)

${ }^{47}$ H. Kim and I.-K. Oh, Jap. J. App. Phys. 53, 03 DA01 (2014)

${ }^{48}$ H. Kim, Thin Solid Films 519, 6639 (2011)

${ }^{49}$ H. B. Profijt, S. E. Potts, M. C. M. Van de Sanden, and W. M. M. Kessels, J. Vac. Sci.

Technol. A. 29, 050801 (2011)

${ }^{50}$ H. C. M. Knoops, T. Faraz, K. Arts, and Wilhelmus M. M. Kessel. J. Vac. Sci. \& Technol. A 37, 030902 (2019)

${ }^{51}$ S.M. Rossnagel, A. Sherman, F. Turner, J. Vac. Sci. Technol. B 18, 2016 (2000)

${ }^{52}$ H. Kim C. Cabral, C. Lavoie, S.M. Rossnagel, J. Vac. Sci. Technol. B 20, 1321 (2002)

${ }^{53}$ E. Langereis, M. Creatore, S.B.S. Heil, M.C.M. Van de Sanden, and W.M.M. Kessels, Appl. Phys. Lett. 89, 081915 (2006)

${ }^{54}$ R. Ovanesyan, E. A. Filatova, S. D. Elliott, D. M. Hausslann, D. C. Smith, and S. Agarwal. J. Vac. Sci. Technol. A 37, 060904 (2019)

${ }^{55}$ H. C. M. Knoops, E. Langereis, M. C. M. Van de Sanden, and W. M. M. Kessels, J. Electrochem. Soc. 157, G241 (2010)

${ }^{56}$ S.V. Nugyuen, IBM Journal of Research and Development 43, 109 (1999) ${ }^{57}$ H. B. Profijt, M. C. M. Van de Sanden, and W. M. M. Kessels, Electrochem. Solid-State Lett. 15, G1-G3 (2012)

${ }^{58}$ A. Chaker, C. Vallée, V. Pesce, S. Belahcen, R. Vallat, R. Gassilloud, N. Posseme, M. Bonvalot, and A. Bsiesy, Appl. Phys. Lett. 114, 043101 (2019)

${ }^{59}$ S. Belahcen, M. Bonvalot, T. Yegohyan, C. Vallée, A. Bsiesy. To be published

${ }^{60}$ M. Koster, and H. M. Urbassek, Phys. Rev. B. 63, 224111 (2001)

${ }^{61}$ T. Takagi J. Vac. Sci. Technol. A 2, 382 (1984)

${ }^{62}$ A.J. M. Mackus A.A. Bol, and W.M. M. Kessels, Nanoscale 6, 10941 (2014)

${ }^{63}$ A.J.M. Mackus, M.J.M. Merkx, W.M.M. Kesselsl, Chemistry of Materials 31, 2 (2019)

${ }^{64}$ K. Cao, J. Cai, X. Liu, and R. Chen, J. Vac. Sci. Technol. A 36, 010801 (2018)

${ }^{65}$ R. Clark, K. Tapily, K.-H. Yu, T. Hakamata, S. Consiglio, D. O’Meara, C. Wajda, J. Smith, and G. Leusink, APL Mater. 6, 058203 (2018)

${ }^{66}$ K. J. Hughes and J.R. Engstrom, J. Vac. Sci. Technol. A 30, 01 A102 (2012)

${ }^{67}$ R.C. Longo, S. McDonnell, D. Dick, R. M. Wallace, Y.J. Chabal, J.H.G. Owen, J.B. Ballard, J.N. Randall, and K. Cho, J. Vac. Sci. Technol. B 32, 03 D112 (2014) 
${ }^{68}$ B. Kalanyan, P.C. Lemaire, S.E. Atanasov, M.J. Ritz, and G.N. Parsons, Chem. Mater. 28, 117 (2016)

${ }^{69}$ S. E. Atanasov, B. Kalanyan, and G. N. Parsons, J. Vac. Sci. Technol. A 34, 01 A148 (2016)

${ }^{70}$ D. Dick, J.B. Ballard, R.C. Longo, J.N. Randall, K. Cho, and Y.J. Chabal, J. Phys. Chem. C 120, 24213 (2016)

${ }^{71}$ A.J. M. Mackus, N. Leick, L. Baker, W.M.M. Kessels, Chem. Mater 24, 1752 (2012)

${ }^{72}$ M. Yan, Y. Koide, J. R. Babcock, P. R. Markworth, J. A. Belot, T. J. Marks, and R. P. H. Chang, Appl. Phys. Lett. 79, 1709 (2001)

${ }^{73}$ R. Chen, H. Kim, P. C. Mclntyre, and S. F. Bent, Appl. Phys. Lett. 84, 4017 (2004)

${ }^{74}$ M.H. Park, Y.J. Jang, H.M. Sung-Suh, and M.M. Sung, Langmuir 20, 2257 (2004)

${ }^{75}$ K.J. Park, J.M. Doub, T. Gougousi, and G. N. Parsons, Appl. Phys. Lett. 86, 051903 (2005)

${ }^{76}$ R. Chen, and S. F. Bent, Adv. Mater. 15, 1086 (2006)

${ }^{77}$ E. Färm, M. Kemell, M. Ritala, and M. Leskelä, Chem. Vap. Deposition 12, 415 (2006)

${ }^{78}$ E. Farm, M. Vehkamaki, M. Ritala, and M. Leskelä, Semicond. Sci. Technol. 27, 074004 (2012)

${ }^{79}$ M. Fang and J.C. Ho, ACS Nano 9 (2015) 8651

${ }^{80}$ F.S.M. Hashemi, C. Prasittichai, and S.F. Bent, ACS Nano 9, 8710 (2015)

${ }^{81}$ A. Mameli, M.J.M. Merkx, B. Karasulu, F. Roozeboom, W. M. M. Kessels, and A. J. M. Mackus, ACS nano 11, 9303 (2017)

${ }^{82}$ R. Vallat, R. Gassilloud, B. Eychenne, and C. Vallée, J. Vac. Sci. Technol. A 35, 01B104 (2017)

${ }^{83}$ R. Vallat, R. Gassilloud, O. Salicio, K. El Hajjam, G. Molas, B. Pelissier, and C. Vallée, J. Vac. Sci Technol. A 37, 020918 (2019)

${ }^{84}$ M.F.J. Vos, S.N. Chopra, M.A. Verheijen, J.G. Ekerdt, S. Agarwal, W.M.M. Kessels, A.J. M. Mackus, Chem. Mater. 31, 3878 (2019)

${ }^{85}$ S.K. Song, H. Saare, and G.N. Parsons, Chem. Mater. 3, 4793 (2019)

${ }^{86}$ W. H. Kim, F. S. M. Hashemi, A. J. M. Mackus, J. Singh, Y. Kim, D. Bobb-Semple, Y. Fan, T. Kaufman-Osborn, L. Godet, and S. F. Bent, ACS Nano 10, 4451 (2016)

${ }^{87}$ J K. Sprenger, H. Sun, A.S. Cavanagh, and S.M. George, J. Vac. Sci. Technol. A 36, 01A118 (2018)

${ }^{88}$ J.K. Sprenger, H. Sun, A.S. Cavanagh, A. Roshko, P.T. Blanchard, and S.M. George, J. Phys. Chem. C 122, 9455 (2018)

${ }^{89}$ M. Hirayama and S. Sugawa, Jpn. J. Appl. Phys. 58, 110902 (2019) 